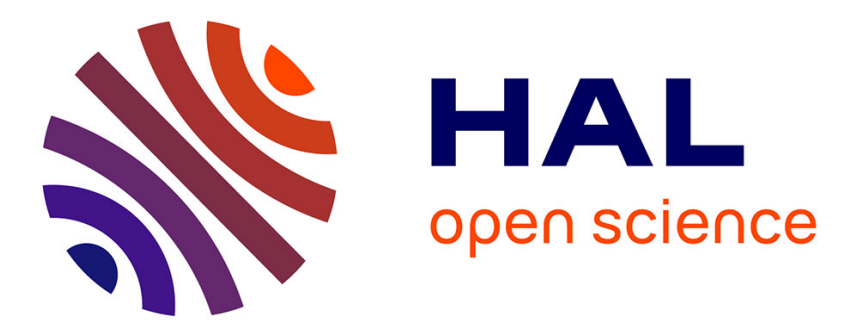

\title{
The Raman signature of protonic species as a potential tool for dating or authentication of glazed pottery
}

Burcu Kirmizi, Stephen Chen, Philippe Colomban

\section{To cite this version:}

Burcu Kirmizi, Stephen Chen, Philippe Colomban. The Raman signature of protonic species as a potential tool for dating or authentication of glazed pottery. Journal of Raman Spectroscopy, 2019, 50 (5), pp.696-710. 10.1002/jrs.5558 . hal-02182333

\section{HAL Id: hal-02182333 \\ https://hal.sorbonne-universite.fr/hal-02182333}

Submitted on 12 Jul 2019

HAL is a multi-disciplinary open access archive for the deposit and dissemination of scientific research documents, whether they are published or not. The documents may come from teaching and research institutions in France or abroad, or from public or private research centers.
L'archive ouverte pluridisciplinaire HAL, est destinée au dépôt et à la diffusion de documents scientifiques de niveau recherche, publiés ou non, émanant des établissements d'enseignement et de recherche français ou étrangers, des laboratoires publics ou privés. 
The Raman signature of protonic species as a potential tool for the dating/authentication of glazed pottery

Burcu Kırmız ${ }^{1,2}$, Stephen Chen $^{3}$, Philippe Colomban ${ }^{1}$

${ }^{1}$ Sorbonne Université, CNRS, MONARIS UMR 8233, Campus Pierre et-Marie Curie, 4 Place Jussieu, 75005 Paris, France

${ }^{2}$ On leave from: Mimar Sinan Fine Arts University, School of Conservation and Restoration of Movable Cultural Property, Cumhuriyet Mahallesi Silahşör Caddesi No:71, Bomonti/Şişli, 34380 Istanbul, Turkey

${ }^{3}$ Royal Heritage Ceramics Authentication Ltd., Room 212, 16W, Hong Kong Science Park, Shatin, Hong Kong

\begin{abstract}
In this study, the potential of Raman spectroscopy is discussed for the comparative dating/authentication of glazed ceramics on the basis of the Raman signature of protonic species incorporated in the glazes due to the corrosion processes as a function of time, chemical composition and environmental conditions. According to the literature and analyses on a reference set of glass samples which had been previously subjected to heavy corrosion in laboratory conditions and extensively studied by Infrared spectroscopy, the accumulation of protonic species such as water and hydroxyl groups on the surface of the silicates gives rise to a specific Raman signature in the 2000$3700 \mathrm{~cm}^{-1}$ range. The intensity of the related bands of this Raman signature is mainly considered to act as a means of discriminating between old and modern artefacts. In order to check this hypothesis, glazed ceramics with different origins (Chinese and Vietnamese stoneware/celadons, blue-and-white and painted enamelled porcelains; Islamic pottery) and different chemical compositions/processing conditions from a wide time span ( 1000 to present) were analysed by Raman microspectroscopy. Further comparative data was obtained by modifying the experimental parameters such as the laser wavelength, objective magnification and confocal hole. The results showed that the Raman intensity of the protonic species shows a correlation with age for lead free glazed pottery in the case of celadons and porcelains. The intensity strongly depends on the chemical composition of the glaze as well as the conservation conditions to a certain degree.
\end{abstract}

Keywords: water; dating; authentication; glazed pottery; glass corrosion 


\section{INTRODUCTION}

Dating of ancient artefacts, especially the ones with inorganic composition (no carbon), has always been a focal point in archaeological research which consequently led to the development of several scientific methods for dating in the $20^{\text {th }}$ century. Among these artefacts of inorganic origin, objects made of glassy silicates (natural and synthetic glass, glazed pottery, enamelled objects etc.) have been one of the major interests in dating research for the last decades. Given the fact that all glassy objects corrode in the course of time as a function of their chemical composition and environmental conditions, attempts have been made to date archaeological glasses on the basis of measuring the thickness of their corrosion layers formed as a function of time. ${ }^{[1]}$ In terms of glass corrosion, it has been known for a very long time that the most important factor is the presence of (acidic) water in the environment. ${ }^{[2-6]}$ In that case, protonic species primarily tend to replace the alkali ions such as $\mathrm{K}^{+}$, $\mathrm{Na}^{+}, \mathrm{Li}^{+}, \mathrm{Mg}^{2+}$ in the glass network by their hydrogen ions $\left(\mathrm{H}^{+}\right.$and $\left./ \mathrm{orH}_{3} \mathrm{O}^{+}\right)$on the basis of an interdiffusion process. The hydrogen ions, namely the protons therefore cause the diffusion of these network modifiers out of the glass network, breaking some of the Si-O-Si links. This process has also mechanical effects on the glass due to the changes in the microstructure in the form of defects (stress, microcracks and voids) ${ }^{[2,4,7,8]}$ and it is expected that the number of these defects will be increased as a function of time and hence the reactivity of the glass is enhanced. The thickness of the so-called corroded layer will thus increase in a non-linear way, leading to the possibility of dating/authentication of the old artefacts. Water molecules and hydroxyl groups are also adsorbed inside the (highly porous) corrosion layers as in the case of oxide surfaces ${ }^{[9-11]}$ to saturate the dangling bonds and hence the increases in the specific surface area will increase the amount of water molecules adsorbed. All of these species containing protons (including water) which react with glass form bonds at the molecular level by hydrogen bonding (either strong or weak). As a result, glass (and glaze) corrosion induces water, proton and/or $\mathrm{OH}^{-}$incorporation in the surface region of the glassy silicate. This has been clearly demonstrated for potash stained glasses at the millimetre/submillimetre scale, both by Optical and Scanning Electron Microscopy, Thermogravimetry as well as by Infrared and Raman spectroscopy. ${ }^{[7-10]}$ A late study about the very surface analyses of rock crystal objects made up of quartz, a more stable type of silicate than man-made glass, by nuclear techniques also shows the time-dependent penetration of "hydrogen" in this very stable mineral, but at the submicron scale. ${ }^{[12]}$ The uptake of water from the environment as a function of time was also qualitatively observed in ancient obsidian ${ }^{[13]}$ and quartz ${ }^{[14]}$ artefacts. Raman microspectroscopy is now a well established technique for the characterization of covalently bonded compounds as those constituting ceramics and glass. Furthermore, mobile Raman set-up allows the fast identification of crystalline and amorphous phases in a non-intrusive way on-site ${ }^{[15]}$ and the use of the technique has also developed rapidly for the authentication of glass, pottery and enamelled objects. ${ }^{[15-18]}$ Raman spectroscopy is an optical technique which is directly influenced by the optical properties of the materials analyzed, such as the transparency and colour. The selection of high magnification microscope objectives allows the specific analysis of the near surface of artefacts. The transparency of a glass is very much affected by the presence of defects on the surface as well as some other surface-deposited materials as a result of corrosion processes. ${ }^{[19]}$ It has been demonstrated that the absolute as-recorded Raman intensity (glass signature) at the surface of rather similar types of glass objects which were preserved in the same/similar conditions decreases as a function of time and thus can be used for the purpose of comparative dating. ${ }^{[6,17]}$ The identification of protonic species (water, hydroxyl groups) in glass can be performed by Raman spectroscopy, but better by Infrared 
(strong bands between 2500 and $3800 \mathrm{~cm}^{-1}$ ) and Near Infrared (overtones and combination bands) absorption/reflexion methods ${ }^{[7,8,20]}$ due to the strong dipolar character of $\mathrm{X}-\mathrm{H}$ bonds. However, the Infrared methods require a flat, glossy surface or a sample preparation procedure in the form of thin samples or powder dispersed in $\mathrm{KBr}$ or Csl solid pellets or in Nujol ${ }^{\mathrm{TM}}$ or Fluorolube ${ }^{\mathrm{TM}}$ mulls, which is destructive and time-consuming. The low intensity of the near infrared signature allows measuring the transmission through thick and optically clear (polished) samples (>mm). However, as a scattering technique, Raman spectroscopy requires no preparation of the sample. ${ }^{[15,16,19]}$ Preliminary measurements have pointed out the presence of protonic species signature in the Raman spectrum of ancient glazed pottery recorded at the very surface. ${ }^{[16]}$ The signature of the protonic species obtained in the $2000-3700 \mathrm{~cm}^{-1}$ range and their relative intensity could be used as a potential tool for the discrimination of old and modern artefacts, i.e. the genuine artefacts and copies/fakes and for the comparison of samples with an unknown age.

In order to test the potential of this method, we present here a comparison of the Raman signal recorded on twenty glazed ceramics of different origin (Chinese and Vietnamese stoneware/celadons, blue-and-white and painted enamelled porcelains, Islamic pottery) from different time periods (the beginning of the $11^{\text {th }}$ century to the present, including modern fakes). The ceramic samples were selected on the basis of their 'conservation' history (excavated from soil or from shipwreck) and glaze compositions, hence different chemical resistance towards corrosion: high-melting temperature porcelain (feldspar-based glaze), medium celadon and stoneware (calcium-rich glaze) and terra cotta (lead-based glaze). Five different corroded glass pieces previously characterized by Raman, IR and $n I R$ spectroscopy ${ }^{[8]}$ were also used as reference for the Raman signatures of the protonic species. The methodological procedure was also discussed with different experimental parameters such as the laser wavelength, objective magnification and confocal opening.

\section{EXPERIMENTAL}

\subsection{Artefacts}

The pottery samples were selected on the basis of three criteria, such as the age of the artefact, its glaze composition and the environmental condition of its preservation (soil, sea) in order to be able to test our hypothesis. Thus, the samples belong to different types of glazed ceramics coming from different cultures and belong to a wide time span from ca $11^{\text {th }}$ century up to the present time (fakes are also included, see Table 1). The reference samples were selected from a previous study on naturally (meteoric water) and artificially corroded (with $\mathrm{H}_{2} \mathrm{SO}_{4}$ ) pieces of stained glass windows (soda-lime and potash-lime glass), dating to the $13^{\text {th }}$ to the $19^{\text {th }}$ centuries. They had been obtained from ancient notable cathedrals in France, such as Le Mans and Amiens (Table 2). ${ }^{\left[{ }^{[, 21]}\right.}$ A total of 25 samples were analysed, each of them at least at 2-3 spots.

The first group of samples consists of porcelains displaying different production techniques and mostly belonging to Chinese origin (Table 1, Figure 1). The earliest Chinese porcelain samples are dated to the Ming Dynasty (1368-1644) and belong to the blue-and-white group with underglaze blue decoration. The selected samples along with other similar Chinese blue-and-whites have previously been studied by Raman microspectroscopy (see ${ }^{[22-25]}$ and references herein). The later 
Chinese porcelain samples belong to the different reigns of the Qing Dynasty (1644-1911) with multicolours and include different groups, such as wucai, Famille Rose and fencai. These samples display a range of painting techniques with alkali/earth-alkali based glazes and/or lead-based overglaze (yellow, red etc.) painted decorations. Their detailed descriptions can be found in a very recent study. ${ }^{[25]}$ The last Chinese porcelain sample is a modern fake of the Ming Dynasty blue-and-white. The other porcelain samples are of Vietnamese origin, dating to the Lê Dynasty from the $15^{\text {th }}$ century which had been the period of commercial expansion of Vietnamese pottery to the world, taking advantage of the Ming embargo of exportation. They are the products of the Chu Bau kiln from the north of Vietnam which was one of the most important ceramic production centres during the $15^{\text {th }}$ $16^{\text {th }}$ centuries. $^{[22,26-29]}$ One of the shards had been recovered in the mid-15 ${ }^{\text {th }}$ century Cu Lao Cham shipwreck which was found close to the commercial port of Hoi An in central Vietnam. ${ }^{[28]}$ The excavations of the shipwreck conducted $\sim 80 \mathrm{~m}$ undersea in the late $20^{\text {th }}$ century had revealed a great quantity of Vietnamese ceramics. ${ }^{[26]}$ These glazes have a lime-potash aluminosilicate composition. ${ }^{[22,26]}$

Another category of samples consists of celadons/stoneware with mostly Vietnamese origin (Figure 2). The ancient Vietnamese samples are dated between the $11^{\text {th }}-15^{\text {th }}$ centuries (Ly, Tran and Lê Dynasties, Table 1). ${ }^{[18,26,29]}$ Their glazes have a lime aluminosilicate composition, as in the case for Chinese and Korean celadons. ${ }^{[23,30]}$ Most of the Vietnamese celadons/stoneware dating to the Ly Dynasty were produced in the Ha Lan kilns which is situated in the southeast of Hanoi. ${ }^{[29]}$ The $15^{\text {th }}$ century Vietnamese celadon sample, a product of the Chu Bau kiln, also comes from the excavations of Cu Lao Cham shipwreck. ${ }^{[26,28]}$ The modern Vietnamese celadon is a fake which was produced in the Bat Trang kiln, a famous site always activeclose to Hanoi. This sample has already been analysed. ${ }^{[18]}$ Other celadon samples are dated to the Southern Song Dynasty (1127-1279) in China and Goryeo Dynasty (918-1392) in Korea.

The last category of samples includes glazed terra cottas and tiles from different Islamic production centres, namely Samarkand (Uzbekistan), Termez (Uzbekistan-Afghanistan border) and Ifriqiya (Tunisia) (Figures 2,3). They are mostly dated to the $14^{\text {th }}$ century (Table 1 ). These samples have a different type of glaze composition from the porcelains and celadons with a considerable amount of $\mathrm{PbO}$ due to their lower firing temperature. ${ }^{[31,32]}$ The Afghan and Tunisian glazes are lead based while the Uzbek glaze is of the mixed lead-alkaline type.

\subsection{Methodological Procedure}

Raman spectroscopy analyses on the glazes of the ceramic samples were performed non-invasively using a HR800 LabRam spectrometer (Horiba Scientific Jobin-Yvon) coupled to a BX Olympus microscope equipped with different magnification objectives. Olympus x100 ultra long working distance objective was used in order to be able to analyze the glaze layers more specifically in reproducible conditions whatever the shape of the pottery. The $457 \mathrm{~nm}$ laser line generated by an $\mathrm{Ar}^{+}$ion laser (Coherent) source was mainly used for the collection of the data with the illumination power on the samples of about $6 \mathrm{~mW}$. The blue laser is very efficient in the analysis of glassy materials since it induces strong Raman scattering of the silicates. ${ }^{[33]}$ The glaze layers of the samples were analysed at two different points regardless of the color. The maximum total counting time was 75 minutes while the accumulations ranged from 3 to 50 to increase the signal-to-noise ratio. Each 
point was scanned in two different spectral windows, such as $~ 75-2355 \mathrm{~cm}^{-1}$ for the glass signature and $\sim 2110-4000 \mathrm{~cm}^{-1}$ for mainly the signature of the protonic species with 600 lines grating. This grating provides a large spectral window that allows collecting the $2110-4000 \mathrm{~cm}^{-1}$ range in one shot without the need to combine the spectra as required in the case of using a grating with a high line number. This is very important since it allows the analysis of broad tiny bands. The vibrational modes including the protons are expected in the wavenumber region between 2000 and $3800 \mathrm{~cm}^{-1}$ (the narrow Raman signature of isolated vibrators such as hydroxyl groups being expected in the 3500 $3800 \mathrm{~cm}^{-1}$ range although those of more or less strongly hydrogen-bonded species between 2000 and

$\left.3200 \mathrm{~cm}^{-1}\right) \cdot{ }^{[8,9,20,34-37]}$ Each spectrum obtained in the high wavenumber region was mathematically corrected by using LabSpec 5 software according to the procedure recommended by the instrument supplier for the elimination of the waves arising from the edge filter which become visible when the scattered intensity is very low.

The experimental procedure was extended with the use of a higher magnification objective ( $x 200$ Mitutoyo), a smaller $(100 \mu \mathrm{m})$ confocal hole and a different laser wavelength $(514 \mathrm{~nm})$ in order to compare the quality of the spectra obtained. Our experience in the study of aluminosilicates ${ }^{[33,38]}$ and protonic species ${ }^{[20]}$ convinces us that blue or violet laser lines are the most efficient for the study of silicates due to the factors of the combination of $v^{4}$ dependence of Raman scattering, ${ }^{[19]}$ good efficiency of mirrors and CCD, high laser intensity and pre-resonance of Si-O bond. For the purpose of comparison, representative samples which display a good signal for the protonic species were selected for each step. A very high magnification (x200) objective allows the analysis of the very surface and probes an area of approximately $0.5 \times 0.5 \times 2 \mu^{3}$ to be compared with the area of $2 \times 2 \times 6$ $\mu \mathrm{m}^{3}$ for $\mathrm{x} 100$ objective (measurement based on the procedure reported in reference ${ }^{[39]}$ ). Very high magnification objective gives a very good spectrum by focusing on a single phase, a fluorescence-free grain but requires a more sensitive focus adjustment on the sample by checking the Raman signal while moving the objective at the same time. In this case, the total counting time is usually increased by a factor of 3 . The $514 \mathrm{~nm}$ laser line was also produced by the $\mathrm{Ar}^{+}$ion laser source with an average illumination power of $10 \mathrm{~mW}$ on the samples.

\section{RESULTS}

\subsection{Reference corroded glass samples}

The wave-corrected Raman spectra for the reference glass samples previously studied ${ }^{[8]}$ are given in Figure 4. Raman analyses of these samples with different chemical compositions give variable signatures between $2100-4000 \mathrm{~cm}^{-1}$, assigned to the protonic species at the surface layer of the glass network (Tables 2 and 3). Here, the glasses analysed belong to two types, such as potash-lime glass (sensitive to water corrosion) and soda-lime glass (relatively more stable against corrosion). Figure 4 (b) shows the spectrum of a corroded blue potash-lime type of glass (LM13-15b-1) with a notable Raman signature of protonic species. This sample had been annealed in air at $600^{\circ} \mathrm{C}$ after the corrosion process in boiling $\mathrm{H}_{2} \mathrm{SO}_{4}{ }^{[8]}$ This process actually cleans the very surface of glass and eliminates the poorly $\mathrm{H}$-bonded species. A broad component is observed with sub-maxima at 2700 , 2900 and $3180 \mathrm{~cm}^{-1}$. The broad bands at 2700 and $2900 \mathrm{~cm}^{-1}$ indicate the strong $\mathrm{H}$-bonded species whereas the band at $3180 \mathrm{~cm}^{1}$ is assigned to the water molecules adsorbed the glass surface or within the cracks. ${ }^{[8,16]}$ The spectra of a yellow potash-lime glass (AM13y) (Figure 4c) and a blue soda- 
lime glass (AM19b-2) (Figure 4d) also display somewhat similar Raman signatures of protonic species with weaker intensity. These glass pieces conserved in ambient air after the corrosion process (and washing $)^{[8]}$ show an additional feature at $\sim 3550 \mathrm{~cm}^{-1}$, according to the poorly bonded protonic species ( $\mathrm{OH}^{-}$groups) (Tables 2 and 3). The spectrum of sample LM13b-2 (Figure 4a), a blue potashlime glass which was inserted in $\mathrm{KNO}_{3}$ to exchange protonic species with $\mathrm{K}^{+}$ions shows narrower peaks at 2847, 2877 and $3052 \mathrm{~cm}^{-1}$ characteristic of trapped organic molecules within the cracks. Their signature is very different from that of protonic species in terms of wavenumber and bandwidth. The very narrow peak at around $2325 \mathrm{~cm}^{-1}$ is due to the signature of $\mathrm{N}_{2}$ gas ${ }^{[40]}$ trapped from the air in bubbles during the production of the glaze. Its observation is common in glass, glaze and ceramic body as that of $\mathrm{O}_{2}$ at $1555 \mathrm{~cm}^{-1}$ since the multi-reflection of the light at the bubblematrix interface increases the Raman intensity. The last spectrum corresponds to a blue soda-lime glass (AM19b-1) with no visible signature of protonic species (Figure 4e). This is most probably due to the composition of the sample since soda-lime glasses are more corrosion resistant than the potashlime ones. ${ }^{[8,21]}$

The analyses of these glasses by IR absorption on thick samples gives rise to strong absorption in the same wavenumber range but also in the nIR region (combinations and overtones) and their assignment is well documented (see ${ }^{[8]}$ and references herein). This confirms that Raman microspectrometry allows detecting the signature of the protonic species present in the very surface of the glass, although its sensitivity is less than that of IR and nIR absorption.

\subsection{Choice of the 'best' experimental parameters}

The Raman spectra were compared by using $514 \mathrm{~nm}$ laser wavelength, x200 objective and $100 \mu \mathrm{m}$ confocal hole on the same samples for each experimental step. The analyses with the green laser were performed on samples $Q-r$ and T-p which show stronger signatures of the protonic species with the blue laser (Table 3). The spectra obtained show no signature of the protonic species but some additional cosmic peaks recognised by the one pixel-width (Figures 5.A and S.1). The results confirmed that the blue laser is the most efficient one for the detection of the protonic species. For the objective comparison, sample M-blb was selected due to its strong signal of the protonic species in the glass network (Figure 5.B a-a'; Table 3). Raman analysis of the same sample with the $\times 200$ objective allowed us to obtain a better signal with higher intensity with an apparent feature at 3750 $\mathrm{cm}^{-1}$ which is assigned to the hydroxyl groups (Figure 5.B b-b'). However, the recording time was increased about three times together with the decrease of the signal/noise ratio since the laser spot was much smaller. Here, it should be noted that it is impossible to analyse the same point with different high magnification objectives and the $\mathrm{OH}^{-}$groups are probably distributed heterogeneously. For the confocal hole comparison, analyses were performed on sample T-p also showing a strong signal with the standard parameters (Figure 5.C a-a'; Table 3). The intensity of the Raman signal was also increased with the use of a smaller confocal hole but the $\mathrm{OH}^{-}$peak at $3510 \mathrm{~cm}^{-1}$ was no longer visible, perhaps due to some local heating that eliminates the very surface and/or poorly $\mathrm{H}$-bonded species (Figure 5.C b-b').

\subsection{The glaze signature}


The silicate glasses may comprise a wide range of compositions based on the different types of their raw materials which are mainly the fluxes such as potash, soda, lime and lead. ${ }^{[30]}$ In the history of glazed ceramics, different types of glass compositions had been used in the preparation of the glazes according to the availability of the raw materials, the technical competence of the period (kiln maximal temperature) and the experimentations of the craftsmen. ${ }^{[23,30]}$ All types of glassy silicates give a characteristic Raman spectrum which mainly consists of two broad bands found at $\sim 500 \mathrm{~cm}^{-1}$ and $\sim 1000 \mathrm{~cm}^{-1}$. These are the Si-O bending and Si-O stretching modes, respectively which display the fundamental vibrational modes of the $\mathrm{SiO}_{4}$ tetrahedral units making up the glass network. ${ }^{[33,41-43]}$ The incorporation of different types of fluxes in the silicate structure has a direct effect on the Raman signature in terms of the spectral position of the bands and their relative intensities. Thus, the evaluation of these parameters in the Raman spectra enables us to identify different composition types. ${ }^{[33,38,41-47]}$ The different components of the $\mathrm{SiO}_{4}$ stretching bands arise from the different population of the $\mathrm{SiO}_{4}$ tetrahedra in the form of isolated and more or less connected arrangements. It has been pointed out both experimentally ${ }^{[45-46]}$ and by modelling ${ }^{[47]}$ that the area ratio of bending to stretching band is directly related to the degree of polymerization of the $\mathrm{SiO}_{4}$ vibrational (and chemical) unit and hence to the melting temperature of the glass.

The representative Raman spectra obtained from the glazes of the ceramic samples are given in Figure 6. All the spectra display the characteristic Raman signature of a silicate type of glass: two broad features at about 450 and $1000 \mathrm{~cm}^{-1}$ which represent the $\mathrm{SiO}_{4}$ bending and stretching modes, respectively. ${ }^{[45-47]}$ For the porcelain glazes with silica-rich composition which have a high melting temperature (ca. 1350-1400 $\mathrm{cm}^{-1}$ ), the bending mode band is much stronger than the stretching one (Figure $6 a, b, d, e) \cdot{ }^{[46]}$ An opposite behaviour is observed for low temperature melting lead-rich glazes (ca. $700-800^{\circ} \mathrm{C}$ ) such as in the case of Islamic terra cotta glaze (Figure 6f) and the lead-based overglaze of the Qing Chinese porcelain sample (Figure 6h). Several narrow peaks (quartz at $465 \mathrm{~cm}^{-1}$, wollastonite at $585 \& 985 \mathrm{~cm}^{-1}$ ) are also observed in some of the glaze spectra arising from the crystalline precipitates within the glaze. ${ }^{[33,46]}$ The durability of the glaze is directly related to its chemical composition as in the case of feldspar-based porcelain glazes where the addition of aluminium increases the chemical stability. ${ }^{[48]}$ On the contrary, lead-rich glass can easily be corroded by water. ${ }^{[49]}$

We will first discuss the data regarding the lead-glazed terra cottas, (the a priori more reactive glaze with low polymerization index), then those of celadons (firing at higher but medium temperature) and porcelains in which the glaze is fired at high temperature and has the maximal index of polymerization, i.e. the less number of exchangeable cations.

\subsection{Glazed terra cottas}

The wave-corrected Raman spectra for the glazed terra cottas are given in Figure 7 on the top. The Raman signal of the protonic species is rather strong since these glazes have a high reactivity due to the lead-based composition. In particular, the yellow coloured glaze of the sample from Afghanistan (Termez) (T-p) displays a strong signal with the broad features at 2700 and $2950 \mathrm{~cm}^{-1}$ (Table 3; Figure 7a-top). Here it should be noted that the yellow pigments used are rich in lead which is a factor also contributing to the corrosion process. The 'narrow' peak at $3510 \mathrm{~cm}^{-1}$ which is assigned to the hydroxyl groups is also significant (and seems associated to the lead-based glaze, see further). The spectra of the other glazed terra cottas are also rather similar, showing the broad features of the $\mathrm{H}$ - 
bonded species but with variable intensities (Figure $7 b, c, d$-top). In fact, the white glaze of the Tunisian sample (T-bb) displays the least marked signal among the others. Additionally, the blue glaze of the sample from Tunisia (T-b) displays an apparent very broad band at $3550 \mathrm{~cm}^{-1}$ rising from the $\mathrm{OH}^{-}$groups as well as the $\mathrm{N}_{2}$ gas peak at $2325 \mathrm{~cm}^{-1}$ (Table 3). Please note that all of the samples are dated to the same time-period.

\subsection{Glazed celadons/stoneware}

Figure 7-bottom compares the wave-corrected spectra obtained from the celadons/stoneware which have a lime-based composition. The stoneware sample (Ly-bo) which is one of the oldest samples from the $12^{\text {th }}$ century shows a very strong Raman signal of the protonic species (Figure 7a-bottom). The broad features at 2700 and $2950 \mathrm{~cm}^{-1}$ are again visible, displaying the $\mathrm{H}$-bonded species found in the glass network. Additional features at $3170 \mathrm{~cm}^{-1}$ and $3300 \mathrm{~cm}^{-1}$ are also present which are assigned to the water molecules adsorbed on the surface. Another feature at $3730 \mathrm{~cm}^{-1}$ is assigned to the hydroxyl groups (Table 3 ). The spectrum of the $11^{\text {th }}$ century Korean sample (G-cel) is also consistent with that of the stoneware sample, showing a similar but less intense signature (Figure 7bbottom). The spectrum of the Vietnamese sample (Ly-cel 2) shows a rather similar spectrum with lower intensity (Figure 7c-bottom) whereas the spectra of the other ancient celadons represent rather different signatures with varying intensities (Figure 7d,e,f-bottom). After all, the modern celadon sample (F-cel) displays a completely different type of spectrum where actually no signature of the protonic species is visible (Figure 7g-bottom). The big bump peaking at $\sim 3000 \mathrm{~cm}^{-1}$ is characteristic of fluorescence. The peak at $2327 \mathrm{~cm}^{-1}$ is again assigned to $\mathrm{N}_{2}$ gas. Thus, the signatures of the protonic species obtained in the celadon/stoneware samples seem to be in correlation with their ages but other factors should also be considered such as the mechanical damage (cracks, pores) as a function of the degree of corrosion in relation with the calcium-based glaze composition.

\subsection{Porcelains}

\section{a) Glazes}

The wave-corrected Raman spectra for the porcelains and the samples excavated from the soil/ the shipwreck are given in Figure 8 - top.

The spectrum of the Ming porcelain (blue underglaze decor, the colourless glaze being fired with the porcelain body) particularly represents a very strong Raman signature of the protonic species ( 2700 and $2900 \mathrm{~cm}^{-1}$ for $\mathrm{H}$-bonded species and $\sim 3180 \mathrm{~cm}^{-1}$ for water) (Table 3; Figure 8b-top). The fake porcelain ( $F-p)$ and the other Ming porcelain (M-blc) show different Raman signatures with the features at 2850 and $3730 \mathrm{~cm}^{-1}$ which result from the $\mathrm{H}$-bonded species and hydroxyl groups respectively (Figure 8d,e-top). In these spectra, fluorescence is also observed in the region 3000-3500 $\mathrm{cm}^{-1}$. In the case of sample F-p, it should be noted that defects might have been made in the glaze to mimic an old appearance but it is not known whether some treatments have been made to "age" the object.

\section{b) Lead-based Overglaze}

The spectrum of the green lead-based overglaze of the Qing Famille Rose porcelain (Q-r) displays a strong Raman signature of the protonic species, with $\sim 2700$ and $2900 \mathrm{~cm}^{-1}$ for $\mathrm{H}$-bonded species and $\sim 3180 \mathrm{~cm}^{-1}$ for water (Table 3; Figure 8a-top). The spectrum of the other green lead-based overglaze 
of the Qing wucai porcelain (Q-bl) displays a well-distinguished band at $2920 \mathrm{~cm}^{-1}$ which is due to the $\mathrm{H}$-bonded species (Table 3; Figure 8f-top) whereas the green enamel of the Qing painted porcelain (Q-p) has a lower intensity signal, but displays an additional peak at $3560 \mathrm{~cm}^{-1}$ which is assigned to the hydroxyl groups (Figure 8c-top). This peak seems to be characteristic of the corroded lead-based glaze.

\subsection{Samples excavated or recovered from shipwreck}

Figure 8-bottom compares the wave-corrected Raman spectra of the Vietnamese porcelains/celadons either being excavated or recovered in the $\mathrm{Cu}$ Lao Cham shipwreck. These samples are expected to have been exposed to more active corrosion conditions as a result of their long term stay in sea water. The spectrum of the porcelain sample from the $15^{\text {th }}$ century shipwreck (Lê-bw) displays bands at 2700, 2940 and $3230 \mathrm{~cm}^{-1}$ which are assigned to $\mathrm{H}$-bonded species and water respectively (Table 3; Figure 8a-bottom). The other samples show different types of Raman spectra with varying intensities (Figure 8b-d-bottom). Consequently, it can be proposed for both sample categories that the composition of the glazes and the environmental conditions are other factors to be considered affecting the Raman signature of the protonic species together with the age.

\section{DISCUSSION}

As mentioned before, the Raman intensity obtained is directly related to the optical properties of the materials analyzed since Raman spectroscopy is an optical technique. The absolute Raman intensity of the silicate signature was found to be an effective tool in the discrimination of similar types of glassesas a function of time according to theirvarying degrees of corrosion which in turn affect the transparency of glass. ${ }^{[6,17]}$ The relative intensity of the Raman signature of protonic species incorporated in the glassy silicate network on the glass/glaze surface was also previously proposed as a potential tool for the discrimination of artefacts (kept in the same conditions) as a function of age. ${ }^{[16]}$ The results of our analyses on different types of glazed ceramic samples showed that there is a correlation between the relative intensity of the Raman signature of the protonic species and the age of the artefact to a certain degree including the celadon/stoneware and porcelain samples. For the comparison of all the data obtained, a plot of $\mathrm{H}_{2} \mathrm{O} / \mathrm{OH}$ band area as an indicator of Raman intensity of the protonic species versus elapsed time since production date was drawn where $Y$ scale is logarithmic and $X$ scale is taken as inverse time (assuming an Arrhenius law for the protonic species) ${ }^{[11]}$, including the regression lines for the sample groups(Figure 9 ). The band area is calculated for each spectrum by visual examination (the procedure is described in more detail in Supplementary Materials, Figure S.2). The fitting lines were determined by Origin software tool using a linear regression analysis. It should be noted that the error of area measurement is about $\pm 10 \%$. In Figure 9, we observe a similar slope for celadons/stoneware and porcelain glazes, lower than that of stained glass. . With the mathematical representation used,the band area depends exponentially on the inverse elapsed time and the slope of the fitting line is similar to an activation Energy, as in the case of the expression of ion diffusion versus time following the Arrhenius rule. Thus, rather similar activation energy is thus observed for the celadons/stoneware and porcelain glazes while a much higher one is the case for stained glasses. It was not possible to determine the parameter according to the linear regression for the terra cotta glazes due to the lack of similar modern samples. However, when the data for the terra cotta glazes and the porcelain overglazes are considered 
together in linear regression analysis, the slope (activation energy) of the fitting line is even higher than that of stained glasses, making the line almost horizontal. Thus, we can strongly suggest that these observations are consistent with the chemical composition of the regarding sample groups. In the case of stained glasses, the potash based composition makes them less resistant to corrosion due to the easy exchange of $\mathrm{K}^{+}$ion with $\mathrm{H}_{3} \mathrm{O}^{+}$ion. ${ }^{[8]}$ However, the celadons/stoneware and porcelain samples display glazes with a higher durability due to their lime and feldspar based composition, making them corrode relatively slower than stained glass. On the other hand, the lead-based terra cotta glazes and porcelain overglazes are the most corroded since the effect of composition is dominant concerning the amount of lead which increases the reactivity of the glaze. As a result, the correlation between time and Raman intensity is mostly valid for the sample groups which are the most resistant to corrosion. However, it is also clear that more data are necessary to build the empirical law concerning the " $\mathrm{H}_{2} \mathrm{O} / \mathrm{OH}^{\prime}$ " band area as a dating tool. It should also be noted that spectra from each sample were recorded on 2 spots in this study. Obviously, a statistical approach could improve the efficiency of the method, especially if only one type of object is studied.

Figure S.3 shows the as-recorded and wave-corrected spectra of the Qing Famille Rose porcelain (Qr) obtained from preliminary measurements performed on the section of shards at different distances from the glaze surface in the high wavenumber region. ${ }^{[25]}$ Unfortunately, in this preliminary work the selected wavenumber window $\left(3000-3800 \mathrm{~cm}^{-1}\right)$ being too small hinders the clear observation of all the components. However, the measurements show very well that the intensity is relatively stronger at $3170 \mathrm{~cm}^{-1}$, just at the limit of the window in the spectrum which is the closest one to the surface (Figure S.3left). This is due to the fact that the corrosion phenomenon is initiated at the very surface of glass due to the presence of protonic species (water) resulting in the formation of a corrosion layer (hydration layer). As expected, the more distant spectrum represents almost no signal of the protonic species. In the case of focusing towards the inner structure of glaze, the signal of the protonic species is lost due to the limited thickness of the corroded layer (see also Figure S.4 for the low wavenumber region from the glaze towards the paste). It is thus important to use a high magnification microscope objective ( $\times 100$ or $\times 200)$ and to focus the spot precisely at the very surface of the sample.

\section{CONCLUSION}

In this study, the possibility of a comparative dating/authentication procedure on the basis of the Raman signature of the protonic species accumulated at the surface of glass is investigated for the first time by using a selection of glazed ceramic samples from different origins and time periods (from ca $11^{\text {th }}$ century up to the present time). As in the case of the absolute Raman intensity collected from similar types of glasses with varying degrees of corrosion, the evaluation of the relative Raman intensity of the protonic species signature at the sample surface proved to be useful as a means of comparative dating/authentication especially for celadons/stoneware and porcelain samples which have a lead free chemical composition. The modern fakes can also be identified by no visible signature of protonic species but a fluorescence signal. We can conclude that the information about the age of a pottery can be obtained by this procedure depending strongly on the glaze composition and weakly on the conservation conditions. The method appears to be more appropriate to detect fakes than to provide an accurate dating, thus it can specifically be proposed as 
a fast and non-invasive method for the discrimination between old and modern artefacts

(copies/fakes) in terms of authentication. Obviously, the efficiency of the method will be strengthened with the collection of a series of data for very similar objects.

\section{ACKNOWLEDGMENTS}

Dr. Céline Paris is kindly acknowledged for her advices in the recording of the Raman spectra.

Mr Lee Koon Keung and Li Kong Lung from Royal Heritage Ceramics Authentication Ltd. are acknowledged for many discussions, for the incitation to make this study and for partial support. 


\section{References}

1. R.H. Brill, H.P. Hood, Nature 1961; 189[4758],12-14.

2. R.H. Doremus, J. Non-Cryst. Solids 1975; 19, 137-144.

3. M. Perez y Jorba, J.P. Dallas, C. Bauer, C. Bahezre, J.C. Martin, J. Mater. Sci. 1980; 15[7], 1640-1647.

4. W.A. Lanford, K. Davis, P. Lamarche, T. Laursen, R. Groleau, R.H. Doremus, J. Non-Cryst. Solids 1979; 33[2], 249-266.

5. G.A. Cox, B.A. Ford, J. Mater. Sci. 1993; 28[20], 5637-5647.

6. Ph. Colomban, A. Tournié, J. Cult. Herit. 2007; 8[3], 242-256.

7. M. Vilarigues, R.C. da Silva, J. Non-Cryst. Solids 2006; 352[50-51], 5368-5375.

8. A. Tournié, P. Ricciardi, Ph. Colomban, Solid State lonics 2008; 179[38], 2142-2154.

9. Ph. Colomban, J. Mater. Sci. 1989; 24[8], 3011-3020.

10. V. Vendange, Ph. Colomban, J. Porous Mat. 1996; 3[3], 193-200.

11. Ph. Colomban, A. Novak, in Proton Conductors Solids, Membranes and Gels-Materials and Devices, (Ed. Ph. Colomban), Cambridge University Press, Cambridge, 1992, pp. 272-293.

12. T. Calligaro, Y. Coquinot, I. Reiche, J. Castaing, J. Salomon, G. Ferrand, Y. Le Fur, Appl. Phys. AMater. 2009; 94[4], 871-878.

13. I. Friedman, R.L. Smith, Science 1959; 129[3358], 1285.

14. J.E. Ericson, O. Dersch, F. Rauch, J. Archaeol. Sci. 2004; 31[7], 883-902.

15. P. Ricciardi, Ph. Colomban, A. Tournié, V. Milande, J. Raman Spectrosc. 2009; 40[6], 604-617.

16. Ph. Colomban, J. Raman Spectrosc. 2018; 49[6], 921-934.

17. D. Mancini, A. Tournié, M.-C. Caggiani, Ph. Colomban, J. Raman Spectrosc. 2012; 43[2], 294-302.

18. N. Q. Liem, N. T. Thanh, Ph. Colomban, J. Raman Spectrosc. 2002; 33[4], 287-294.

19. G. Gouadec, Ph. Colomban, Prog. Cryst. Growth Ch. 2007; 53[1], 1-56.

20. Ph. Colomban, Fuel Cells 2013; 13[1], 6-18.

21. Ph. Colomban, M.-P. Etcheverry, M. Asquier, M. Bounichou, A. Tournié, J. Raman Spectrosc. 2006; 37[5], 614-626.

22. G. Şimşek, Ph. Colomban, S. Wong, B. Zhao, A. Rougeulle, N.Q. Liem, J. Cult. Herit. 2015; 16[2], 159-172.

23. F. Zhang, in Ancient Technology to Modern Science, Ceramics and Civilization Series vol. 1, (Ed: W.D. Kingery), American Ceramic Society, Columbus, 1985, pp. 163-179.

24. Y. Qu, J. Xu, X. Xi, C. Huang, J. Yang, Ceram. Int. 2014; 40[6], 8783-8790.

25. Ph. Colomban, F. Ambrosi, A.-T. Ngo, T.-A. Lu, X.-L. Feng, S. Chen, C.-L. Choi, Ceram. Int. 2017; 43[16], 14244-14256.

26. Ph. Colomban, N.Q. Liem, G. Sagon, H.X. Tinh, T.B. Hoanh, J. Cult. Herit. 2003; 4[3], 187-197.

27. J.N. Miksic, in Southeast Asian Ceramics: New Light on Old Pottery, (Ed: J.N. Miksic), Editions Didier Millet, Singapore, 2009, pp: 58-61.

28. B.M. Tri, T.T. Tin, N.Q. Liem, Ph. Colomban, Taoci 2002; 2, 105-110.

29. N. Q. Liem, G. Sagon, V. X. Quang, H. V. Tan, Ph. Colomban, J. Raman Spectrosc. 2000; 31[10], 933-942. 
30. N. Wood, Chinese Glazes: Their Origins, Chemistry and Recreation, University of Pennsylvania Press, Philadelphia, 1999.

31. Ph. Colomban, C. Truong, J. Raman Spectrosc. 2004; 35[3], 195-207.

32. Ph. Colomban, G. Sagon, A. Louhichi, H. Binous, N. Ayed, R. Archaeom. 2001; 25, 101-112.

33. Ph. Colomban, Appl. Phys. A 2004; 79[2], 167-170.

34. D. Hadzi, Pure Appl. Chem. 1965; 11[3-4], 435-454.

35. D. Hadzi, S. Bratos, in The Hydrogen Bond Recent Developments in Theory and Experiments, (Eds: P. Schuster, G. Zundel, C. Sandorfy), North Holland Publishing Co., Amsterdam, 1976, Chapt. 2.

36. Ph. Colomban, J. Mol. Struct. 1992; 270, 407-416.

37. A. Slodczyk, Ph. Colomban, S. Willemin, O. Lacroix, B. Sala, J. Raman Spectrosc. 2009; 40[5], 513521.

38. Ph. Colomban, A. Tournié, L. Bellot-Gurlet, J. Raman Spectrosc. 2006; 37[8], 841-852.

39. M. Havel, Ph. Colomban, SPECTROSCOPY EUROPE-Microscopy and Analysis 2006; 20[3], 11-14.

40. M.L. Frezzotti, F. Tecce, A. Casagli, J. Geochem. Explor. 2012; 112, 1-20.

41. Ph. Colomban, L.C. Prinsloo, in Spectroscopic Properties of Inorganic and Organometallic Compounds vol 40, (Eds: J. Yarwood, R. Douthwaite, S. Duckett), RSC Publishing, Royal Society of Chemistry, Cambridge, 2009, pp. 128-149.

42. Ph. Colomban, in Modern Methods for Analysing Archaeological and Historical Glass, $1^{\text {st }}$ edition, (Ed: K. H.A. Janssens), John Wiley \& Sons Ltd, India, 2013, pp. 275-300.

43. Ph. Colomban, in Analytical Archaeometry: Selected Topics, (Eds: H.G.M Edwards, P. Vandenabeele), Royal Society of Chemistry, Cambridge, 2012, pp. 245-267.

45. Ph. Colomban, J. Non-Cryst. Solids 2003; 323[1-3], 180-187.

46. Ph. Colomban, O. Paulsen, J. Am. Ceram. Soc. 2005; 88[2], 390-395.

47. V. Labet, Ph. Colomban, J. Non-Cryst. Solids 2013; 370, 10-17.

48. R.A. Eppler, D.R. Eppler, Glazes and Glass Coatings, The American Ceramic Society, Westerville, 2000.

49. J. Zarzycki, Glasses and The Vitreous State Cambridge Solid State Science Series, Cambridge University Press, Cambridge, 1991. 
Table 1: The list of samples and their detailed description.

\begin{tabular}{|c|c|c|c|c|c|c|}
\hline $\begin{array}{l}\text { Label } \\
\text { (Figure) }\end{array}$ & Type & Date & Origin & $\begin{array}{l}\text { Remarks } \\
\text { (largest dimension/cm) }\end{array}$ & $\begin{array}{l}\text { Figures } \\
\text { (Spectra) }\end{array}$ & Refs \\
\hline $\begin{array}{l}\text { M-blb } \\
(1 b)\end{array}$ & $\begin{array}{l}\text { Blue-and-white } \\
\text { porcelain }\end{array}$ & $\begin{array}{l}\text { Ming Dynasty } \\
1368-1644\end{array}$ & \multirow[t]{6}{*}{ China } & Feldspar-based glaze (8.5) & 8b-top & \multirow[t]{2}{*}{22,24} \\
\hline $\begin{array}{l}\text { M-blc } \\
(1 \mathrm{c})\end{array}$ & $\begin{array}{l}\text { Blue-and-white } \\
\text { porcelain }\end{array}$ & $\begin{array}{l}\text { Ming Dynasty } \\
1368-1644\end{array}$ & & Feldspar-based glaze (10) & 8e-top & \\
\hline $\begin{array}{l}\text { Q-bl } \\
(1 \mathrm{~g})\end{array}$ & $\begin{array}{l}\text { Wucai porcelain } \\
\text { (blue underglaze; green, } \\
\text { red overglaze) }\end{array}$ & $\begin{array}{l}\text { Qing Dynasty } \\
\text { (Kangxi reign) }\end{array}$ & & $\begin{array}{l}\text { Alkali-lime feldspar-based glaze with } \\
\text { lead-based overglaze (5.5) }\end{array}$ & $8 f$-top & 25 \\
\hline $\begin{array}{l}\text { Q-r } \\
(1 f)\end{array}$ & $\begin{array}{l}\text { Famille Rose porcelain } \\
\text { (blue and green } \\
\text { overglaze) }\end{array}$ & $\begin{array}{l}\text { Qing Dynasty } \\
\text { (Yongzheng } \\
\text { reign) }\end{array}$ & & $\begin{array}{l}\text { Alkali-lime feldspar-based glaze with } \\
\text { lead-based overglaze (9) }\end{array}$ & 8a-top & 25 \\
\hline $\begin{array}{l}\text { Q-p } \\
(1 e)\end{array}$ & $\begin{array}{l}\text { Painted enamelled } \\
\text { porcelain } \\
\text { (blue, red, green and } \\
\text { yellow overglaze) }\end{array}$ & $\begin{array}{l}\text { Qing Dynasty } \\
\text { (Qianlong reign) }\end{array}$ & & Lead-based overglaze (9) & 8c-top & 25 \\
\hline $\begin{array}{l}\text { F-p } \\
(1 a)\end{array}$ & $\begin{array}{l}\text { Blue-and-white } \\
\text { porcelain }\end{array}$ & $\begin{array}{l}\text { "Ming Dynasty" } \\
\text { Fake }\end{array}$ & & Feldspar-based glaze (6.5) & 8d-top & \\
\hline $\begin{array}{l}\text { G-cel } \\
(3 e)\end{array}$ & Celadon & $\begin{array}{l}\text { Goryeo Dynasty } \\
\left(11^{\text {th }} \text { century }\right)\end{array}$ & Korea & Lime glaze (10) & $\begin{array}{l}\text { 7b- } \\
\text { bottom }\end{array}$ & \\
\hline $\begin{array}{l}\text { Ly-cel } 1 \\
\text { (3d) }\end{array}$ & Celadon & $\begin{array}{l}\text { Ly Dynasty } \\
\left(12^{\text {th }}-14^{\text {th }}\right. \\
\text { century })\end{array}$ & \multirow[t]{3}{*}{$\begin{array}{l}\text { Vietnam } \\
\text { (Ha Lan kiln) }\end{array}$} & Lime glaze (5) & $\begin{array}{l}7 f- \\
\text { bottom }\end{array}$ & 18,29 \\
\hline $\begin{array}{l}\text { Ly-cel } 2 \\
(2 d)\end{array}$ & Celadon & $\begin{array}{l}\text { Ly Dynasty } \\
\left(12^{\text {th }}-13^{\text {th }}\right. \\
\text { century })\end{array}$ & & Lime glaze (10) & $\begin{array}{l}\text { 7c- } \\
\text { bottom }\end{array}$ & 18,29 \\
\hline $\begin{array}{l}\text { Ly-bo } \\
\text { (2c) }\end{array}$ & Stoneware & $\begin{array}{l}\text { Ly Dynasty } \\
\left(12^{\text {th }} \text { century }\right)\end{array}$ & & Lime glaze (6.5) & $\begin{array}{l}\text { 7a- } \\
\text { bottom }\end{array}$ & 18,29 \\
\hline $\begin{array}{l}\text { S-cel } \\
(1 \mathrm{~d})\end{array}$ & Celadon & $\begin{array}{l}\text { Southern Song } \\
1127-1279\end{array}$ & China & Lime glaze (4) & $\begin{array}{l}\text { 7e- } \\
\text { bottom }\end{array}$ & 30 \\
\hline $\begin{array}{l}\text { F-cel } \\
(3 f)\end{array}$ & Celadon & Fake & $\begin{array}{l}\text { Vietnam } \\
\text { (Bat Trang kiln) }\end{array}$ & Lime glaze (5) & $\begin{array}{l}\text { 7g- } \\
\text { bottom }\end{array}$ & 18 \\
\hline $\begin{array}{l}\text { Ly-ti } \\
(2 \mathrm{e})\end{array}$ & Glazed tile/celadon & $\begin{array}{l}\text { Ly Dynasty } \\
\left(13^{\text {th }} \text { century }\right)\end{array}$ & Vietnam & Lime glaze (6.5) & $\begin{array}{l}8 \mathrm{~b}- \\
\text { bottom }\end{array}$ & \\
\hline $\begin{array}{l}\text { Lê-bw } \\
(2 \mathrm{a})\end{array}$ & $\begin{array}{l}\text { Blue-and-white } \\
\text { porcelain }\end{array}$ & $\begin{array}{l}\text { Lê Dynasty } \\
\left(15^{\text {th }} \text { century }\right)\end{array}$ & \multirow{2}{*}{$\begin{array}{l}\text { Vietnam } \\
\text { Cu Lao } \\
\text { Cham } \\
\text { shipwreck } \\
\text { (Chù dau kiln) }\end{array}$} & Feldspar-based glaze (3.5) & $\begin{array}{l}\text { 8a- } \\
\text { bottom }\end{array}$ & 26 \\
\hline $\begin{array}{l}\text { Lê-cel } \\
(2 b)\end{array}$ & Celadon & $\begin{array}{l}\text { Lê Dynasty } \\
\left(15^{\text {th }} \text { century }\right)\end{array}$ & & Lime glaze (5) & $\begin{array}{l}\text { 8c- } \\
\text { bottom }\end{array}$ & 26 \\
\hline $\begin{array}{l}\text { Lê-bwp } \\
\text { (1h) }\end{array}$ & $\begin{array}{l}\text { Blue-and-white } \\
\text { porcelain bowl bottom }\end{array}$ & $\begin{array}{l}\text { Lê Dynasty } \\
\left(15^{\text {th }} \text { century }\right)\end{array}$ & $\begin{array}{l}\text { Vietnam } \\
\text { (Chù dau kiln) }\end{array}$ & Feldspar-based glaze (8.5) & $\begin{array}{l}8 \mathrm{~d}- \\
\text { bottom }\end{array}$ & 26 \\
\hline $\begin{array}{l}\text { T-ti } \\
(2 f)\end{array}$ & Glazed terra cotta & $\begin{array}{l}\text { Timurid Dynasty } \\
\left(14^{\text {th }}-15^{\text {th }}\right. \\
\text { century })\end{array}$ & $\begin{array}{l}\text { Uzbekistan } \\
\text { (Samarkand) }\end{array}$ & Lead-alkaline glaze (9) & 7c-top & \\
\hline $\begin{array}{l}\text { T-p } \\
(3 a)\end{array}$ & Glazed terra cotta & $\left(14^{\text {th }}\right.$ century) & $\begin{array}{l}\text { Afghanistan } \\
\text { border } \\
\text { (Termez) }\end{array}$ & Lead-alkaline glaze (7) & 7a-top & 31 \\
\hline $\begin{array}{l}T-b \\
(3 b)\end{array}$ & Blue glazed terra cotta & $\left(14^{\text {th }}\right.$ century $)$ & \multirow[t]{2}{*}{$\begin{array}{l}\text { Tunisia } \\
\text { (Ifriqiya) }\end{array}$} & Lead-based glaze (10) & 7d-top & 32 \\
\hline $\begin{array}{l}\text { T-bb } \\
(3 c)\end{array}$ & $\begin{array}{l}\text { Blue and brown glazed } \\
\text { terra cotta }\end{array}$ & $\left(14^{\text {th }}\right.$ century) & & Lead-based glaze (6) & 7b-top & 32 \\
\hline
\end{tabular}


Table 2: The list of reference stained glass samples with artificial corrosion and their detailed description

\begin{tabular}{|l|l|l|l|l|}
\hline Label & Type (colour) & $\begin{array}{l}\text { Date } \\
\text { (century) }\end{array}$ & Origin & Remarks \\
\hline LM13b-2 & K-Ca glass (blue) & $13^{\text {th }}$ & Le Mans & \\
\hline LM13-15b-1 & K-Ca glass (blue) & circa $13^{\text {th }}$ to $15^{\text {th }}$ & cathedral & Annealed at $600^{\circ} \mathrm{C}$ \\
\hline AM19b-1 & Na-Ca glass (blue) & $19^{\text {th }}$ & $\begin{array}{l}\text { Amiens } \\
\text { cathedral }\end{array}$ & \\
& & $19^{\text {th }}$ & $\mathrm{K}^{+}$ion exchanged \\
\hline AM19b-2 & K-Ca glass (yellow) & $13^{\text {th }}$ & \\
\hline
\end{tabular}

Table 3: The observed Raman band wavenumbers and bandwidths of the samples and their assignments.

\begin{tabular}{|c|c|c|c|c|}
\hline $\begin{array}{l}\text { Wavenumber } \\
\left(\mathrm{cm}^{-1}\right)\end{array}$ & bandwidth & Materials & Assignment & $\begin{array}{l}\text { Corresponding IR } \\
\text { band } \\
\text { wavenumbers } \\
\left(\mathrm{cm}^{-1}\right)^{[8,20]}\end{array}$ \\
\hline 3730 & $\mathrm{n}$ & $\begin{array}{l}\text { stoneware/celadon } \\
\text { porcelain }\end{array}$ & \multirow[t]{4}{*}{ Hydroxyl groups } & \multirow[t]{4}{*}{$3600-3800$} \\
\hline 3560 & $\mathrm{n}$ & porcelain overglaze & & \\
\hline 3550 & $\mathrm{vb}$ & $\begin{array}{l}\text { stained glass } \\
\text { glazed terra cotta }\end{array}$ & & \\
\hline 3510 & $\mathrm{n}$ & glazed terra cotta & & \\
\hline 3300 & $\mathrm{n}$ & stoneware/celadon & \multirow[t]{3}{*}{ water } & \multirow[t]{3}{*}{$3200-3500$} \\
\hline 3230 & $b$ & porcelain (shipwreck) & & \\
\hline $3170-80$ & $\mathrm{~b}$ & $\begin{array}{l}\text { stained glass } \\
\text { porcelain overglaze } \\
\text { stoneware/celadon }\end{array}$ & & \\
\hline 2950 & b & $\begin{array}{l}\text { glazed terra cotta } \\
\text { stoneware/celadon }\end{array}$ & \multirow[t]{5}{*}{$\mathrm{H}$-bonded species } & \multirow[t]{5}{*}{$\begin{array}{l}2800-3500 \\
2000-2500\end{array}$} \\
\hline 2920 & $\mathrm{~b}$ & porcelain overglaze & & \\
\hline 2900 & $\mathrm{vb}$ & $\begin{array}{l}\text { stained glass } \\
\text { porcelain overglaze }\end{array}$ & & \\
\hline 2850 & $\mathrm{n}$ & porcelain & & \\
\hline 2700 & $\mathrm{vb}$ & $\begin{array}{l}\text { stained glass } \\
\text { glazed terra } \\
\text { cottaporcelain } \\
\text { overglaze } \\
\text { /(shipwreck) } \\
\text { stoneware/celadon }\end{array}$ & & \\
\hline
\end{tabular}

$\mathrm{n}$ : narrow, b: broad, vb: very broad 

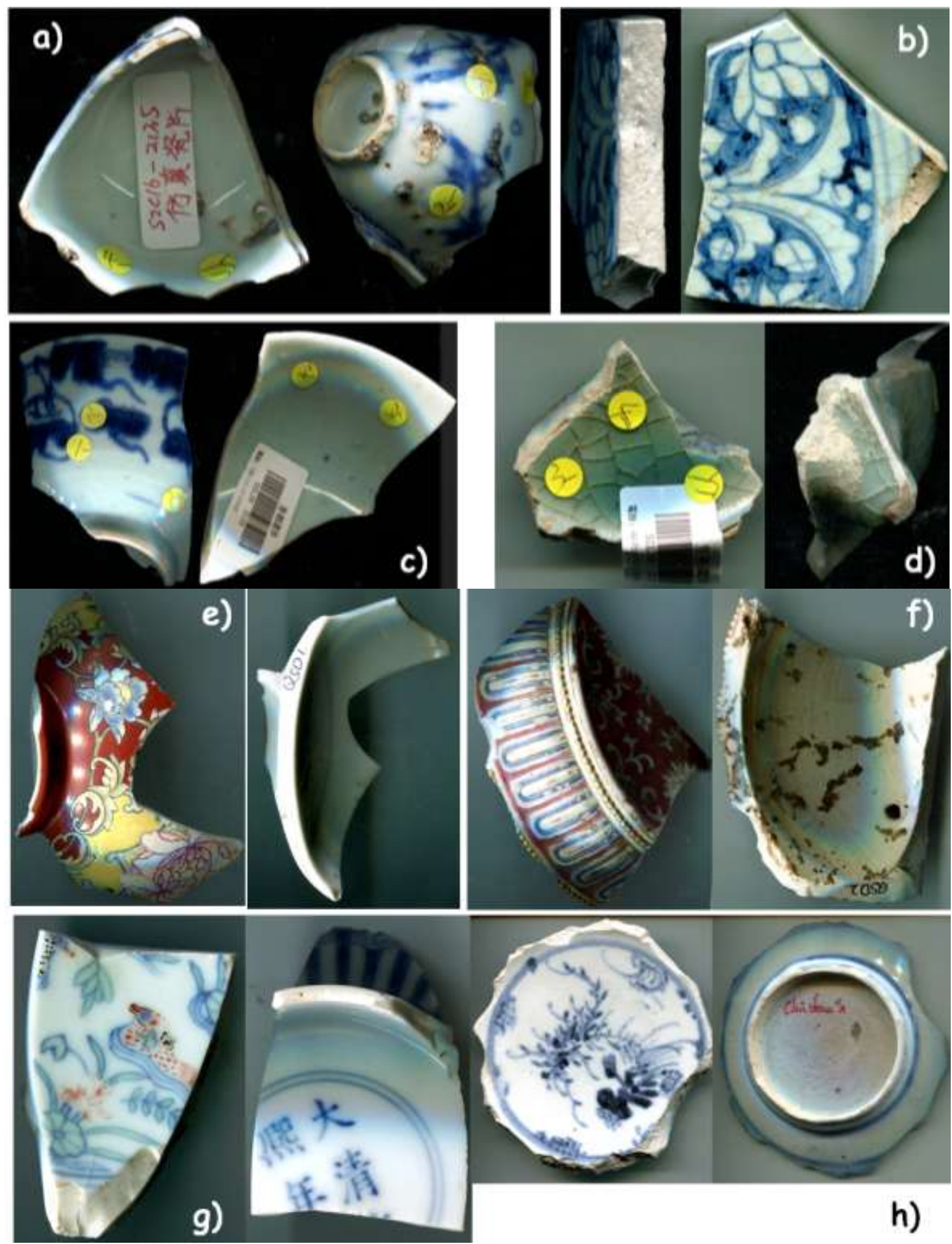

FIGURE 1 Chinese (a: F-p; b: M-blb; c: M-blc; d: S-cel; e: Q-p; f: Q-r; g: Q-bl) and Vietnamese (h: Lêbwp) porcelains and celadon (see Table 1 for details) 

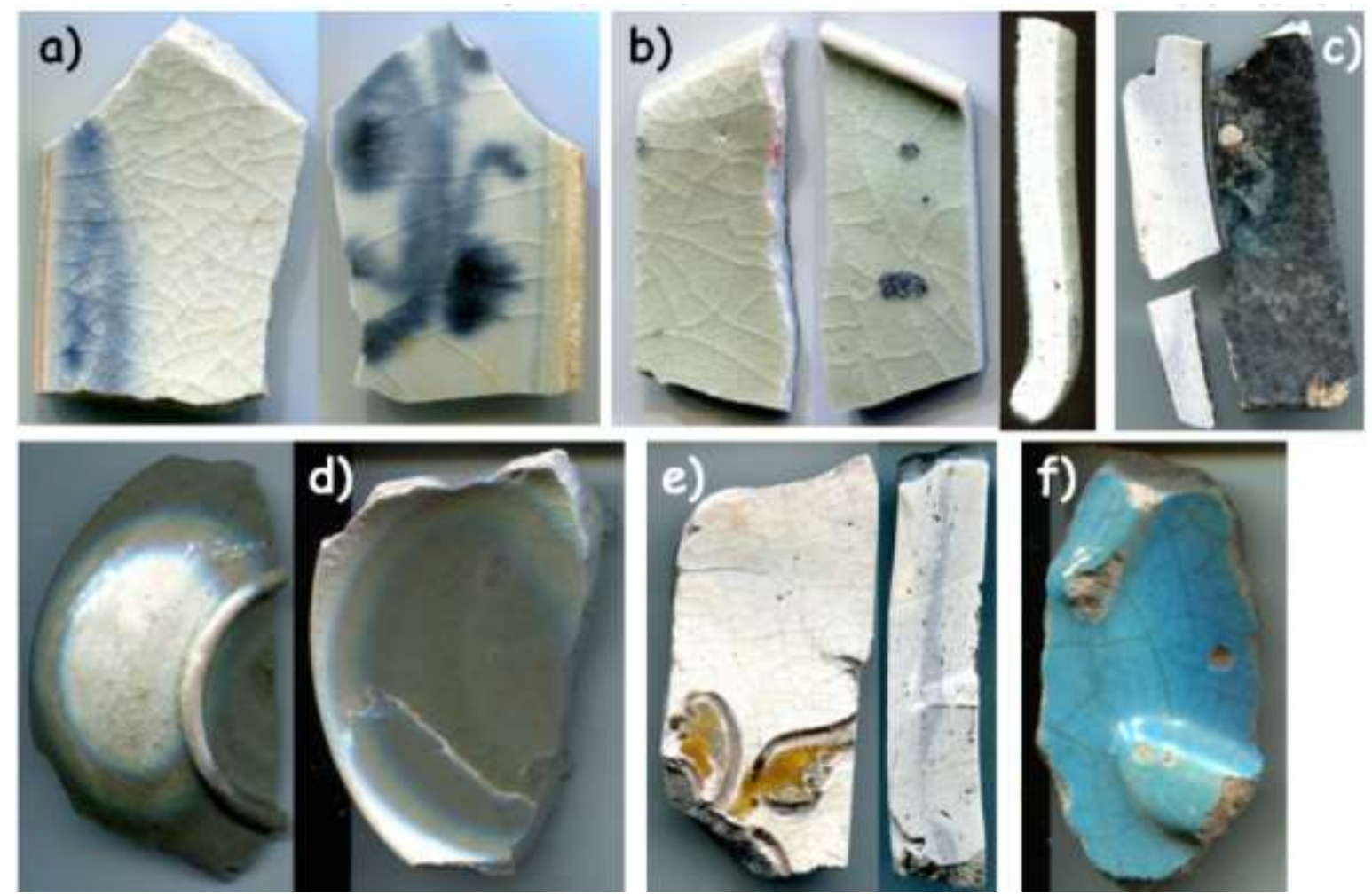

FIGURE 2 Vietnamese pottery (a: Lê-bw; b: Lê-cel; c: Ly-bo; d: Ly-cel2; e: Ly-ti) and glazed terra cotta from Samarkand (f: T-ti) (see Table 1 for details).
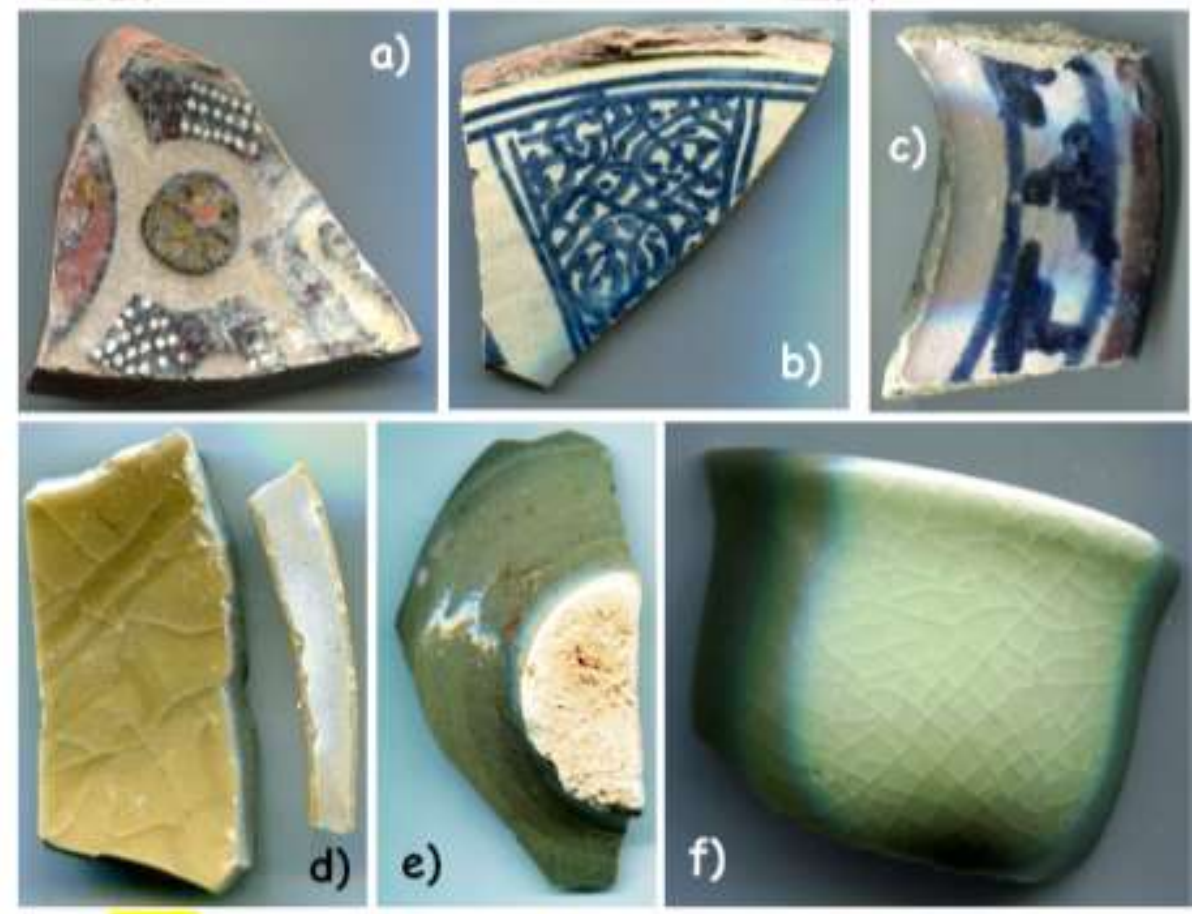

FIGURE 3 Glazed terra cottas from Termez (a: T-p) and Ifriqiya (b: T-b; c: T-bb); Vietnamese (d: Lycel1; f: F-cel) and Korean (e: G-cel) celadons (see Table 1 for details) 


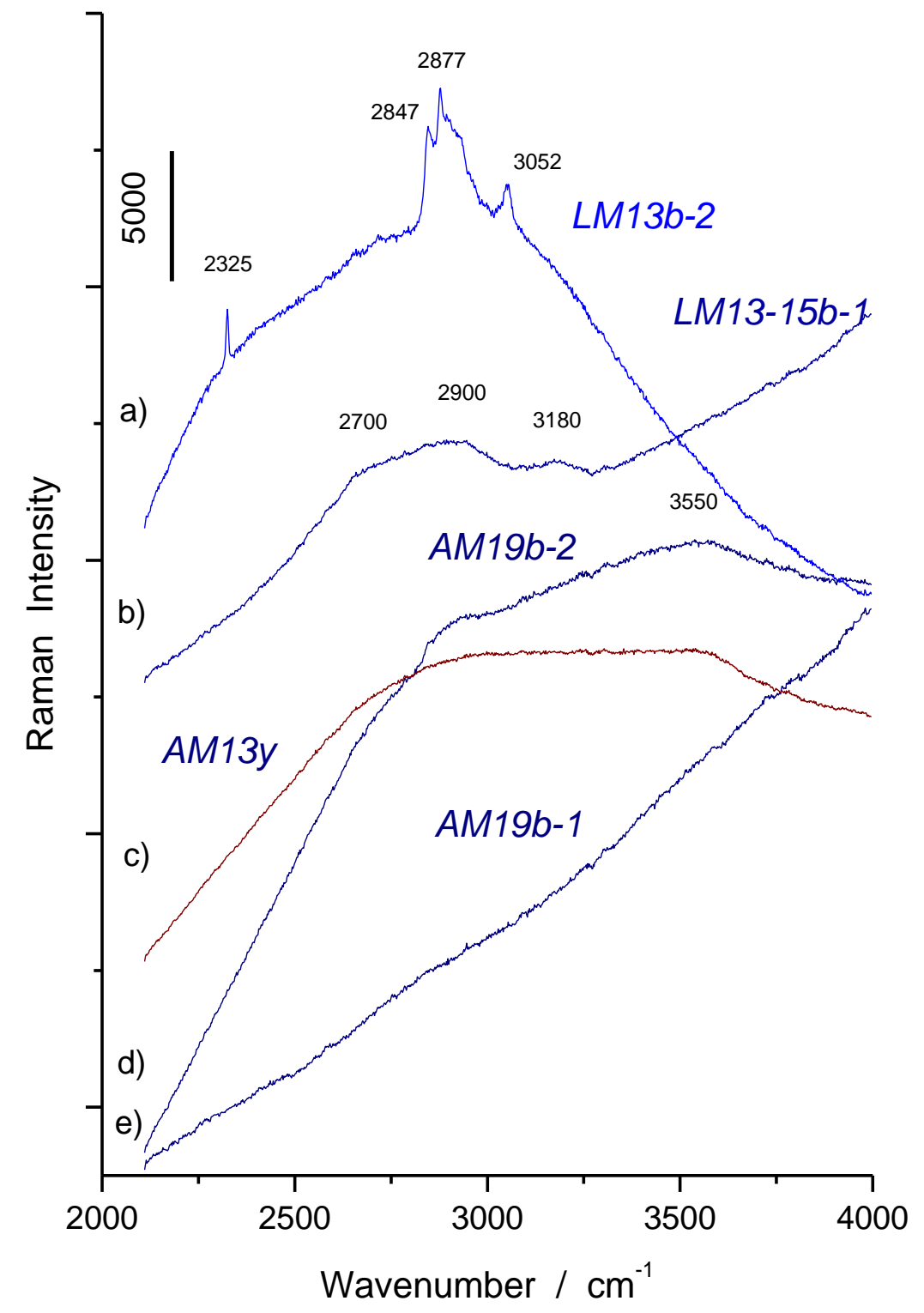

FIGURE 4 Representative wave-corrected Raman spectra recorded on artificially heavy corroded stained glass pieces: lime-potash medieval (LM13b-2, LM 13-15b-1, AM 13y) and soda/potash-lime $19^{\text {th }}$ century glasses (x100 objective; confocal hole: $200 \mu \mathrm{m}$; see Table 2 for more details) 

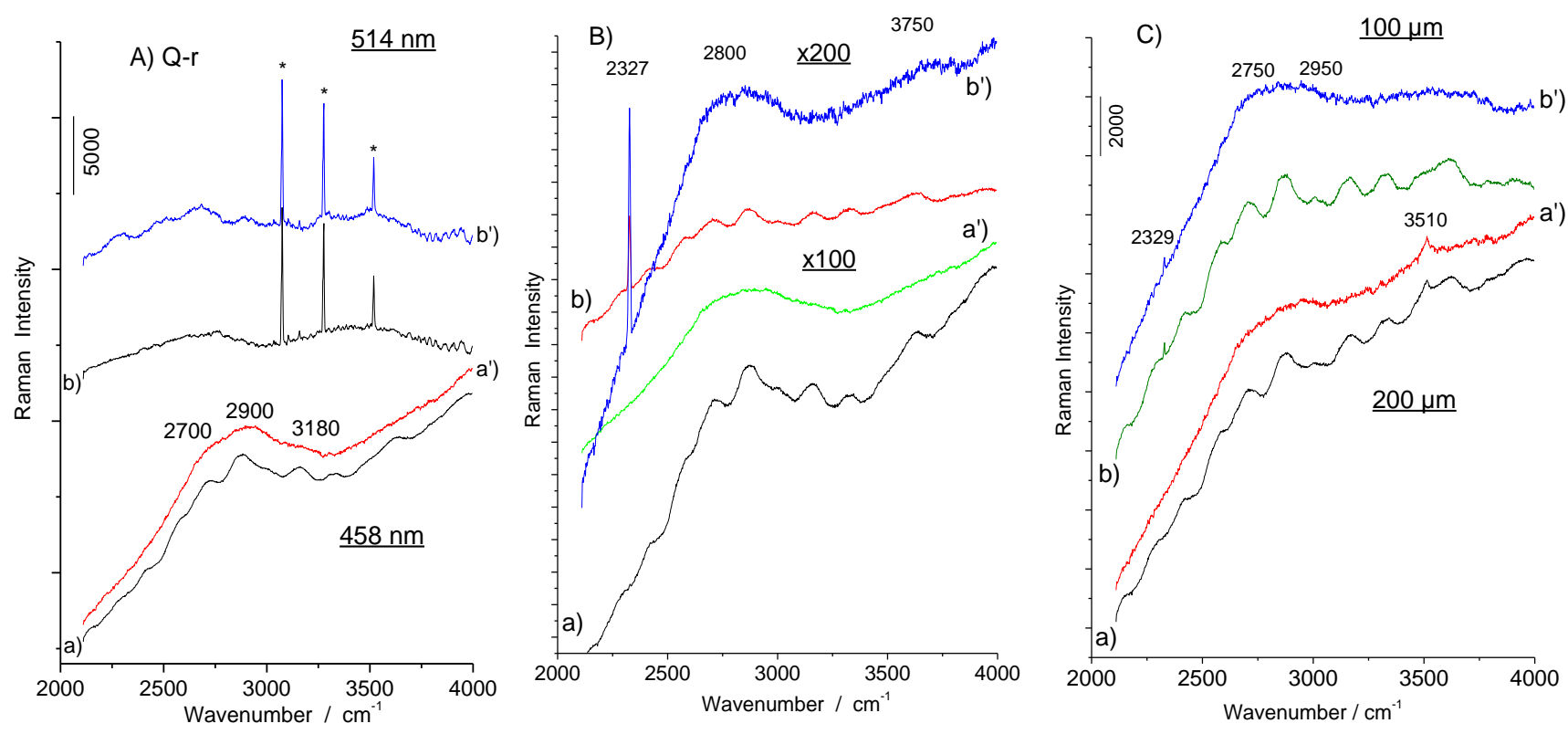

FIGURE 5 Comparison of Raman spectra recorded on the same sample with different experimental parameters: a,b: as recorded; a', $b^{\prime}$ : spectra after subtraction of the waves due to the filtering. A: Spectra of Q-r obtained with green (10 $\mathrm{mW}$ at the sample) and blue ( $6 \mathrm{~mW}$ at the sample) lasers; B: Spectra of M-blb obtained with $\times 200$ and $\times 100$ microscope objectives; C: Spectra of T-p obtained with 100 and $200 \mu \mathrm{m}$ confocal hole, 


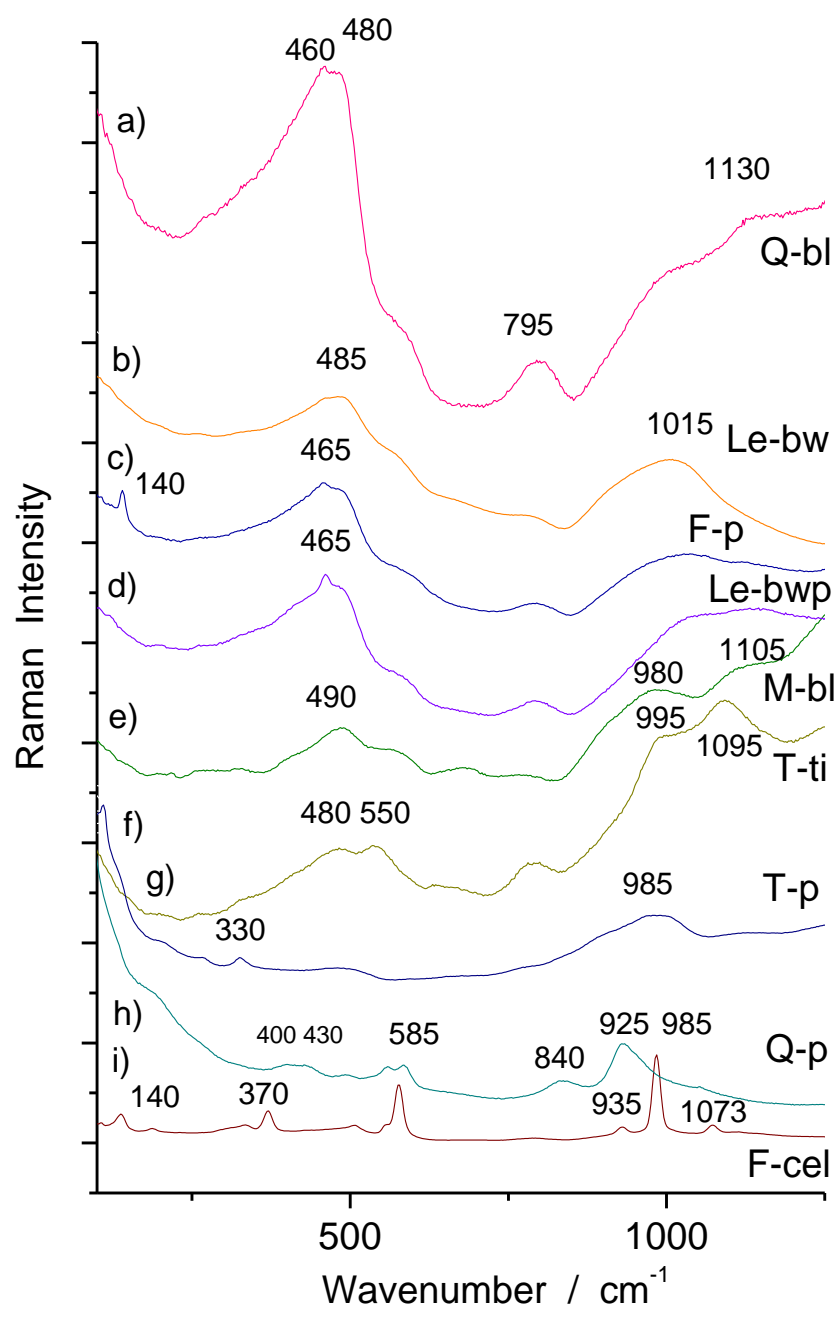

FIGURE 6 Representative Raman spectra of the different types of glazes collected from different coloured areas of the samples (x100 objective; c.h.: $200 \mu \mathrm{m}$ ): a) Q-bl white, b) Lê-bw blue, c) F-p white, d) Lê-bwp white, e) M-blb blue, f) T-p yellow, g)T-ti blue, h) Q-p green, i) Fcel green (see also Table 1 for more details). 


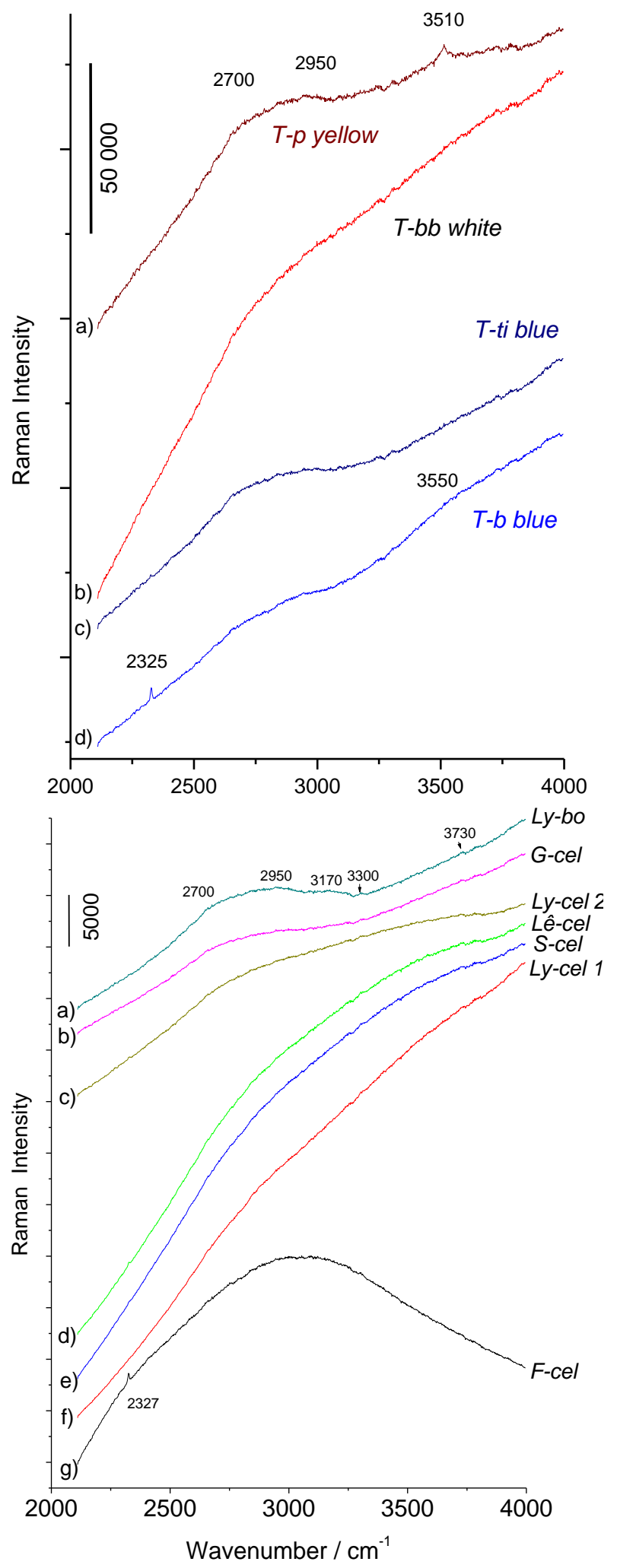

FIGURE 7 Representative wave-corrected spectra recorded on glazed terra cottas (top) and stoneware/celadons (bottom) (x100 objective; c.h.: $200 \mu \mathrm{m}$; see Table 1 for more details) 


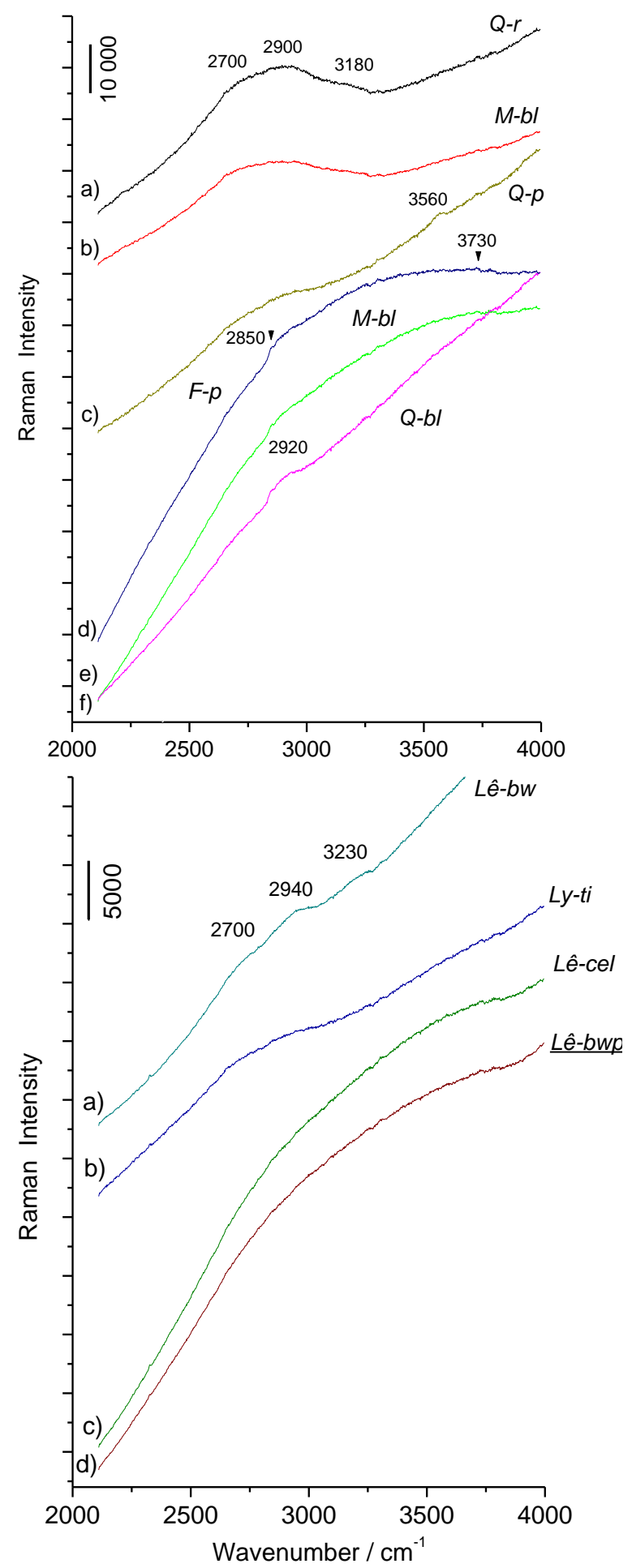

FIGURE 8 Representative wave-corrected spectra recorded on Qing and Ming Dynasty (over)glazed porcelains (top) and Vietnamese porcelains/celadons excavated or from shipwreck (bottom) $(\times 100$ objective; c.h.: $200 \mu \mathrm{m}$; see Table 1 for more details) 


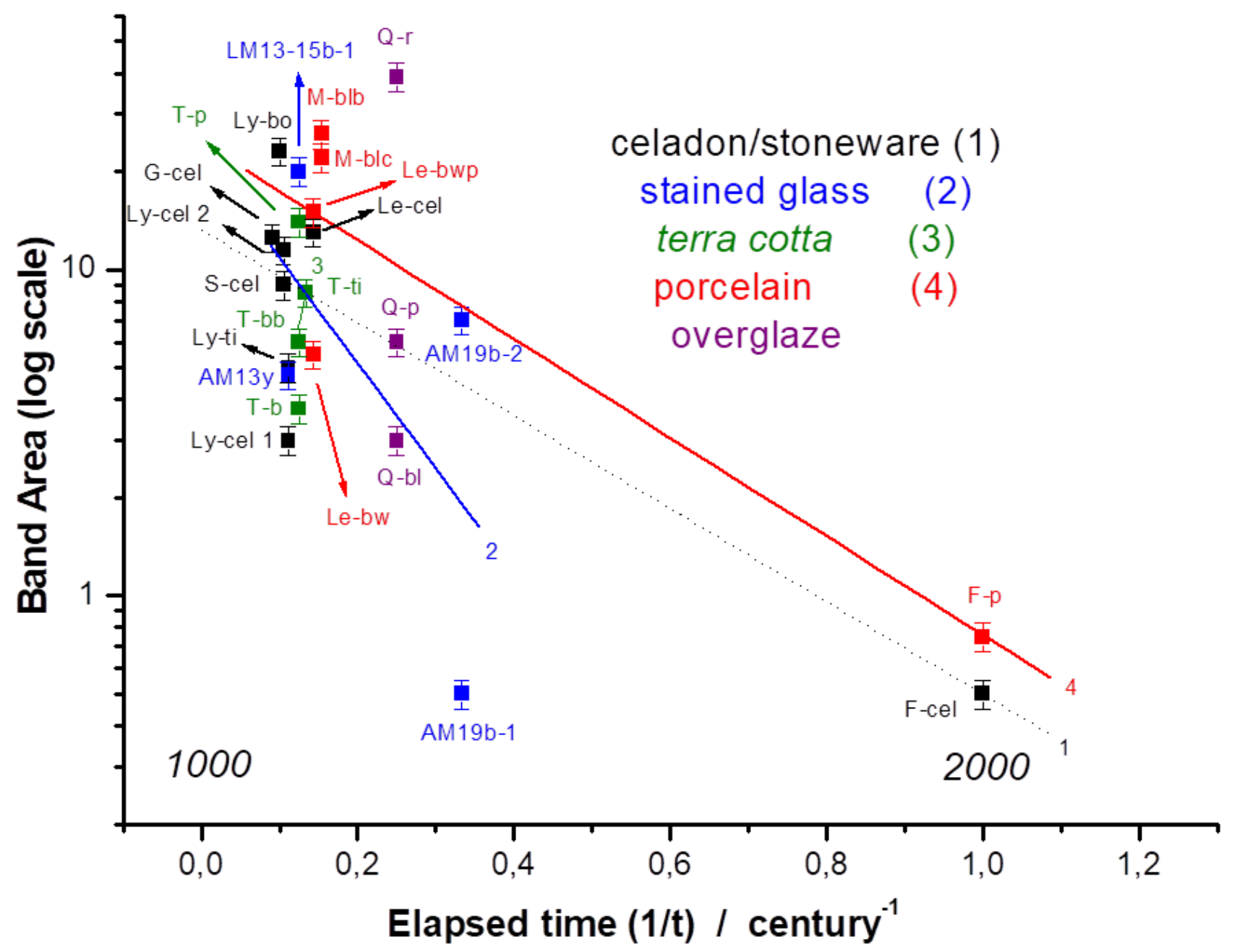

FIGURE $9 \mathrm{H}_{2} \mathrm{O} / \mathrm{OH}$ band area vs. time elapsed since production date for celadons/stoneware, reference stained glasses, glazed terra cottas, porcelains and porcelain overglazes. Regression fitting lines are given indicating the groups. ( $\pm 10 \%$ error bars are included.) 


\section{Supplementary Materials}

The Raman signature of protonic species as a potential tool

for the dating/authentication of glazed pottery

\section{Burcu Kırmızı ${ }^{1,2}$, Stephen Chen $^{3}$, Philippe Colomban ${ }^{1}$}

${ }^{1}$ Sorbonne Université, CNRS, MONARIS UMR 8233, Campus Pierre et-Marie Curie, 4 Place Jussieu, 75005 Paris, France

${ }^{2}$ On leave from: Mimar Sinan Fine Arts University, School of Conservation and Restoration of Movable Cultural Property, Cumhuriyet Mahallesi Silahşör Caddesi No:71, Bomonti/Şişli,

34380 Istanbul, Turkey

${ }^{3}$ Royal Heritage Ceramics Authentication Ltd., Room 212, 16W, Hong Kong Science Park, Shatin, Hong Kong

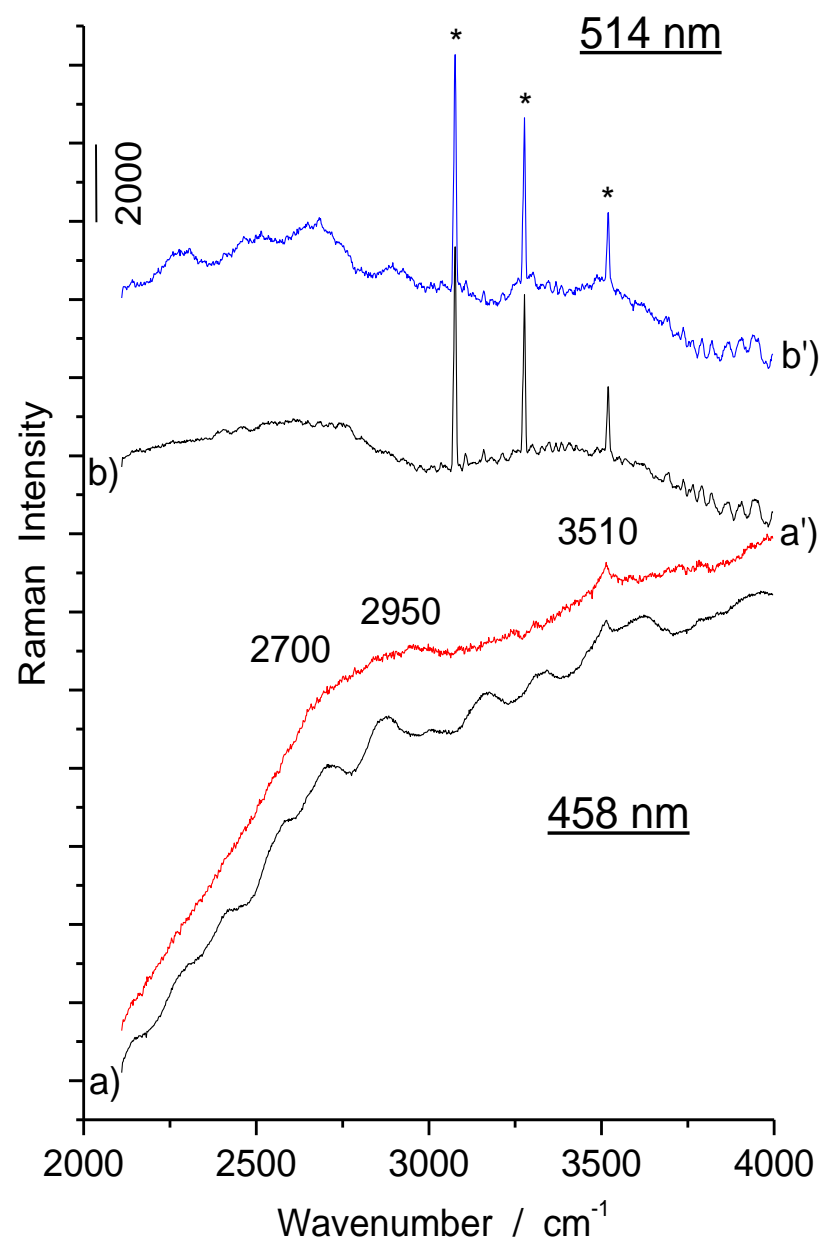


FIGURE S.1 Comparison of Raman spectra recorded on sample (T-p) with different lasers (514 and $458 \mathrm{~nm}$ ); a,b: as recorded; $a^{\prime}, b^{\prime}$ : spectra after subtraction of the waves due to the filtering (x100 microscope objective and $200 \mu \mathrm{m}$ confocal hole ) (see text for details)
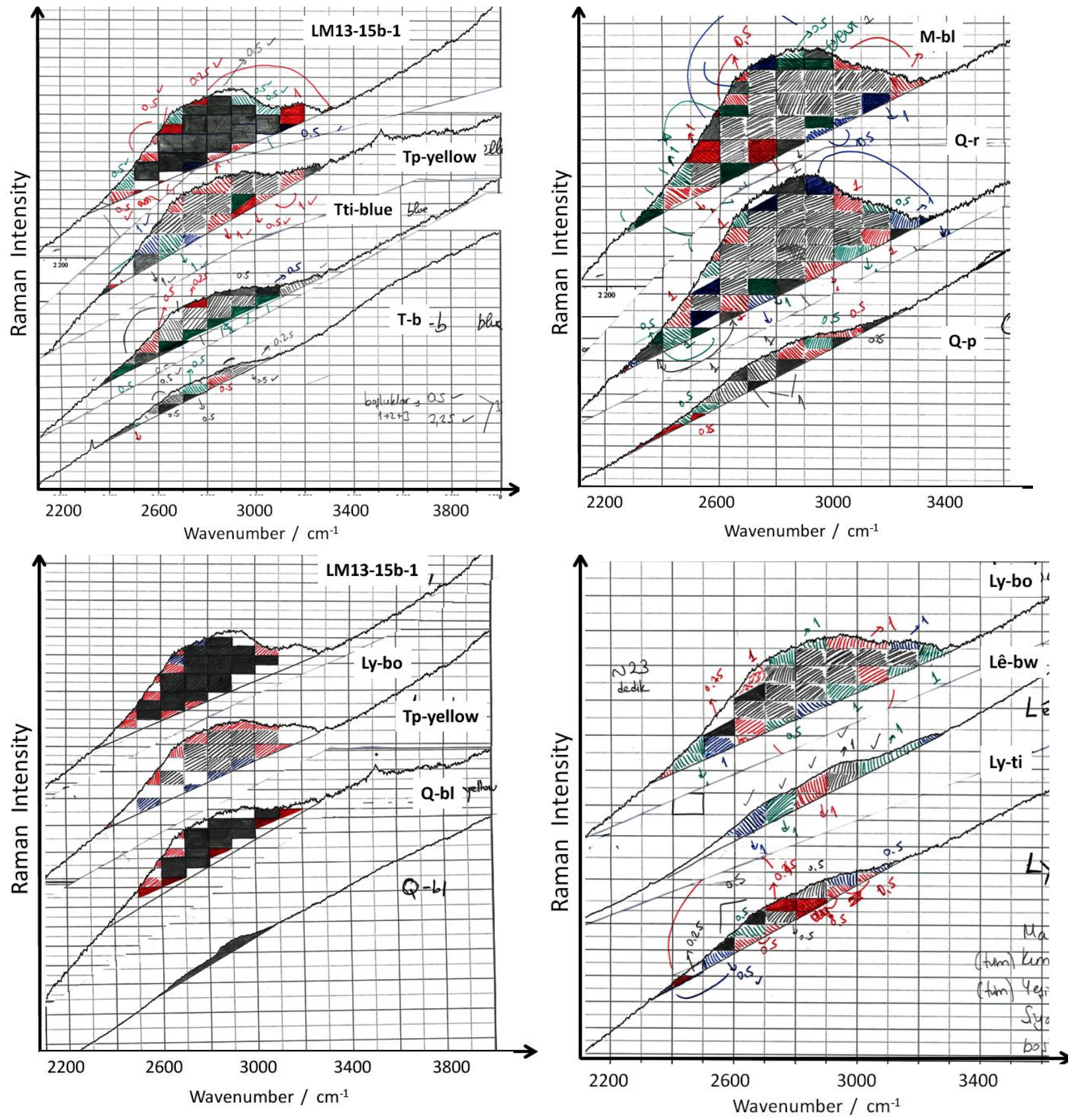

FIGURE S.2 Representative examples of wave-corrected spectra for the calculation of the $\mathrm{H}_{2} \mathrm{O} / \mathrm{OH}$ band area. The band area is calculated by first drawing a baseline under the signature of the protonic species with a ruler and then measuring the area which is generated between the spectrum and the baseline by counting the squares visually. 

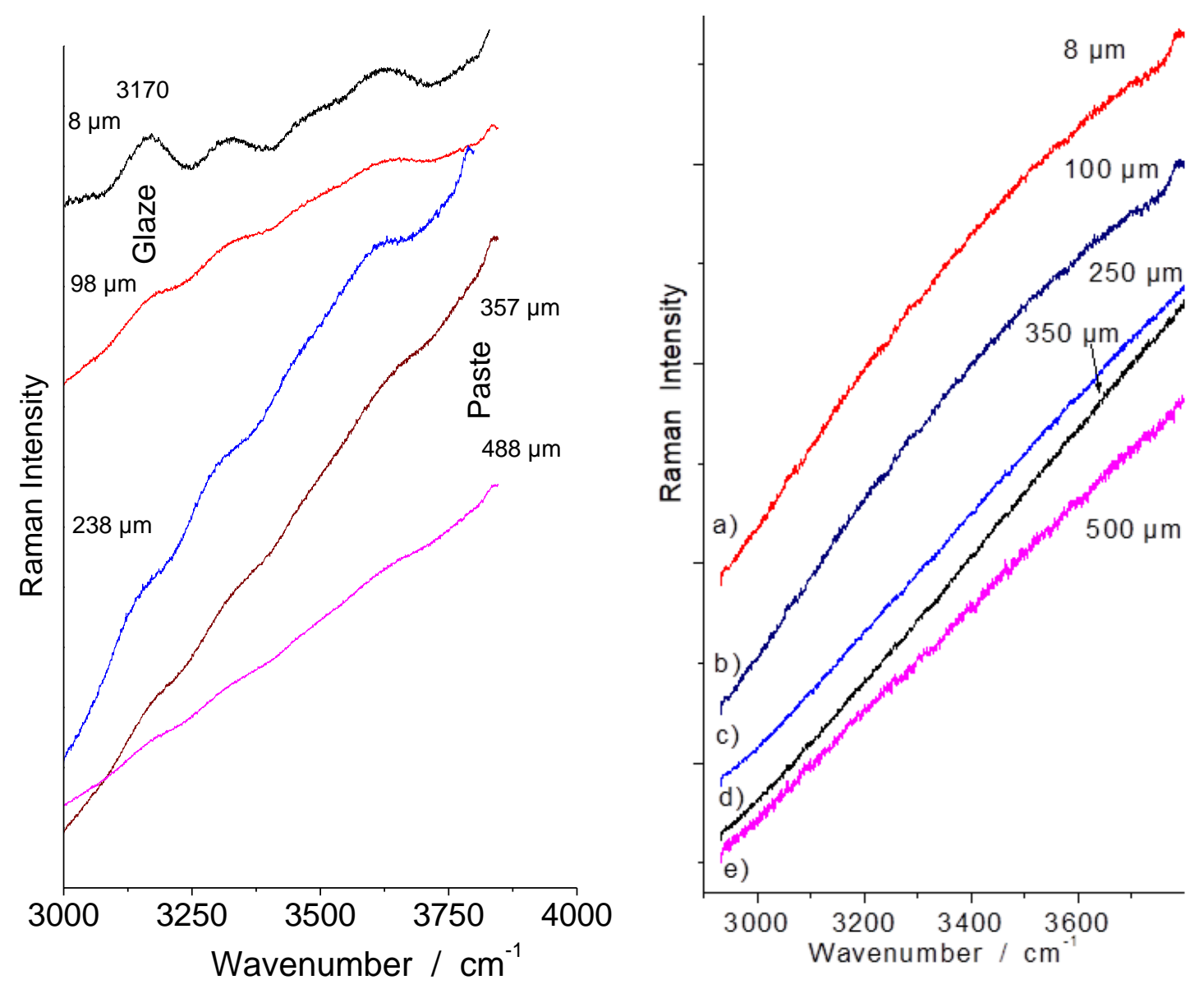

FIGURE S.3 Left: Representative (uncorrected) spectra recorded on Famille Rose (Q-r) porcelain section with $\times 100$ objective (c.h.: $200 \mu \mathrm{m}$ ) at different distances from the glaze surface (note the decreasing intensity of the band from the very surface towards the paste). Right: Corresponding wave-corrected spectra. 


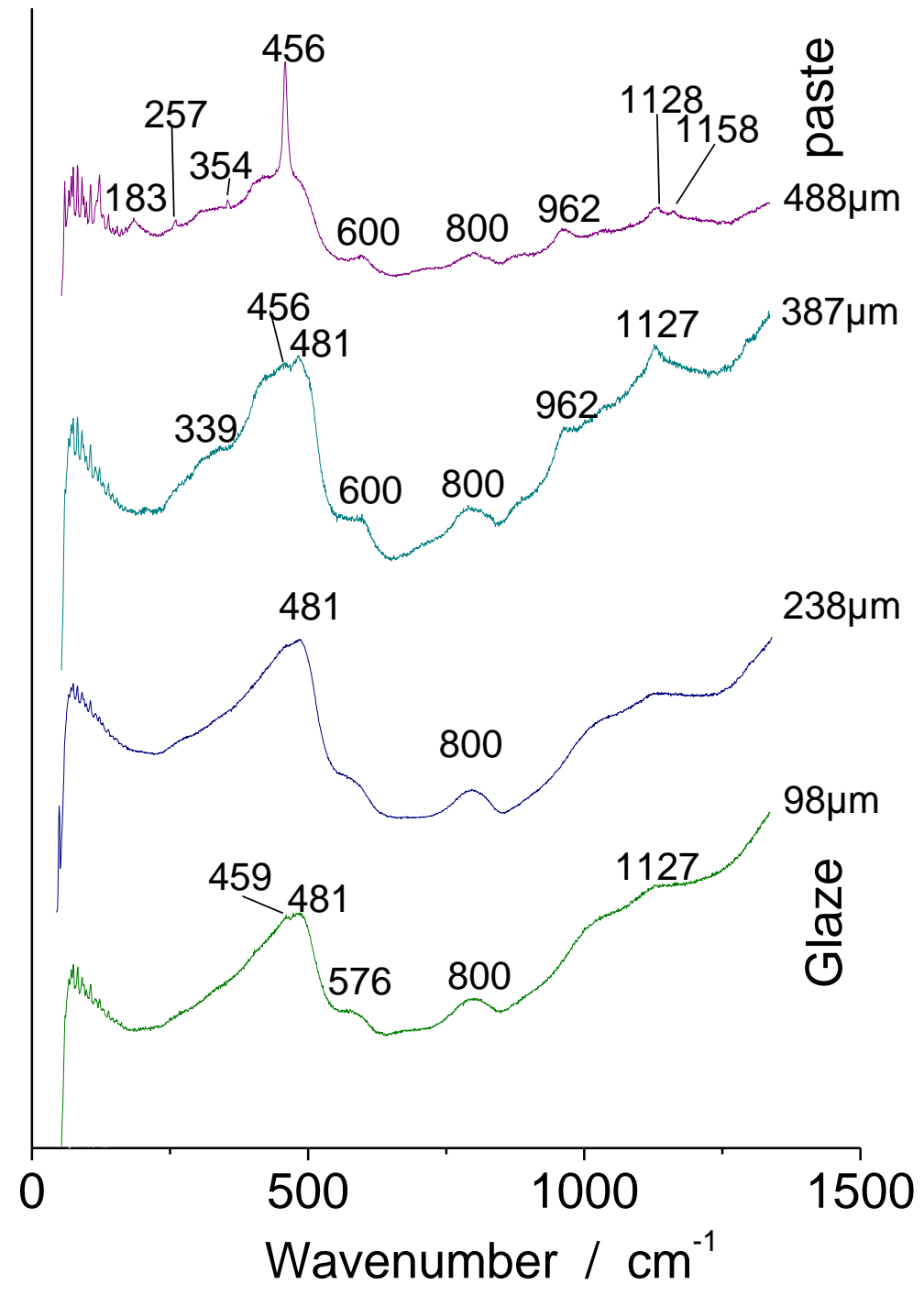

FIGURE S.4 Raman spectra of the glass signature recorded on Famille Rose (Q-r) porcelain section with $\times 100$ objective (c.h.: $200 \mu \mathrm{m}$ ) at different distances from the glaze surface: differentiation between glaze (only broad bands) and porcelain paste is obvious with the superimposition of characteristic mullite narrow peaks at 962 and $1128 \mathrm{~cm}^{-1}$ and in some cases the signature of quartz grain at $183,257,456$ and $1158 \mathrm{~cm}^{-1}$ (see also text). 